University of Windsor

Scholarship at UWindsor

1985

\title{
Locus of control, assertiveness, and anxiety as personality variables in stress-related headaches.
}

Colin. Jones

University of Windsor

Follow this and additional works at: https://scholar.uwindsor.ca/etd

\section{Recommended Citation}

Jones, Colin., "Locus of control, assertiveness, and anxiety as personality variables in stress-related headaches." (1985). Electronic Theses and Dissertations. 2638.

https://scholar.uwindsor.ca/etd/2638

This online database contains the full-text of PhD dissertations and Masters' theses of University of Windsor students from 1954 forward. These documents are made available for personal study and research purposes only, in accordance with the Canadian Copyright Act and the Creative Commons license-CC BY-NC-ND (Attribution, Non-Commercial, No Derivative Works). Under this license, works must always be attributed to the copyright holder (original author), cannot be used for any commercial purposes, and may not be altered. Any other use would require the permission of the copyright holder. Students may inquire about withdrawing their dissertation and/or thesis from this database. For additional inquiries, please contact the repository administrator via email (scholarship@uwindsor.ca) or by telephone at 519-253-3000ext. 3208. 


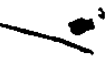

CANADIAN THESES ON MICROFICHE.

\section{THĖSES CANADIENNES SUR MIĊROFICHE}

National Library of Canada

Colloctions Development Branch

Canadian Theses on

Microfiche Service

Ottawa, Canada

K1A ON4
Biblibtheque nationale du Canada

Direction du développement des collections

Service des theses canadlennes

sur microfiche

\section{NOTICE}

The quality of this microfiche is heavily dependent upon the quality of the original thesis submitted for microfilming. Every effort has been made to ensure the highest quality of reproduc. tion possible.

If pages are missing, contact the university which granted the degree.

Some pages may have indistinct print especially if the original pages were typed with a poor typewriter ribbon'or if the untversity sent us an inferlor photocopy.

Previousły copyrighted materials joumal articles, published teşts, etc.) are not filmed.

Reproduction in full of in part of this film is governed by the Canadian Copyright Act, R.S.C. 1970, c. C-30. Please read the authorization forms which accompany this thesis.

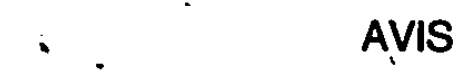

La qualité de cette microfiche dépend grandement de la qualité de la these soumise au microfilmage: Nous avons tout fait pour. assurer une qualité supérieure de reproduction.

S'if manque des pages, veulllez communiquer avec l'université quil a conféré le grade.

La qualite d'impression de.certaines pages peut laisser à désirer, surtout si les pages originales ont été dactylographiees à l'aide d'un ruban usé ou si l'université nous a falt parvenir une photocopie de qualité inférieure.

Les documents quil font déjâ l'objet d'un droit d'auteur (articles de revue, examens publibs, etc.) ne sont pas microfilmés.

La reproduction, meme partielle, de ce microfilm est soumlse a la Lol canadienne sur le drolt d'auteur, SRC 1970, c. C-30. Veullez prendre cọ̀nnaissance des formules d'autorisation qui accompagnent cette these.

c

\section{THIS DISSERTATION \\ HAS BEEN : MICROFILMED EXACTLY AS RECEIVED}

\section{LA THESE A-ÉTE MICROFILMÉE TELLE QUE NOUS L'AVONS: REÇUE}


LOCUS OF .CONTROL, ASSERTIVENESS, AND

ANXIETY ASS PERSONALITY VARIABLES

IN STRESS-RELATED HEADACHES

$$
\begin{array}{ccc}
\cdots & \ddots \\
\text { Colin Jones }
\end{array}
$$

A Thesis

Submitted to the

Faculty of Graduate Studies and Research through the Department of Psychology

in Partial Fulfillment

of the Requirements for the Degree of

Master of Arts

at the University of Windsor

Windsor, Ontario, Canada

- 1985 


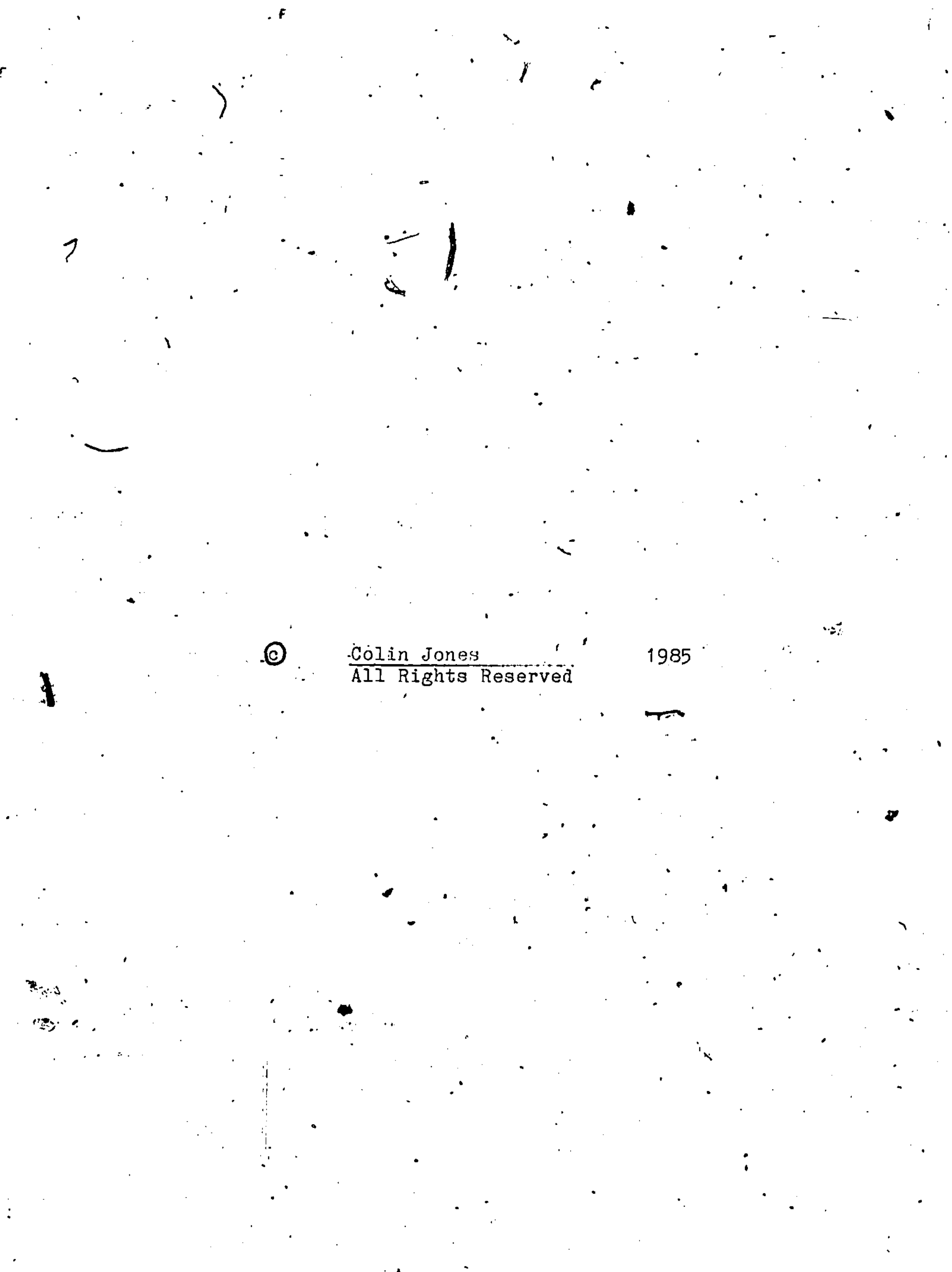




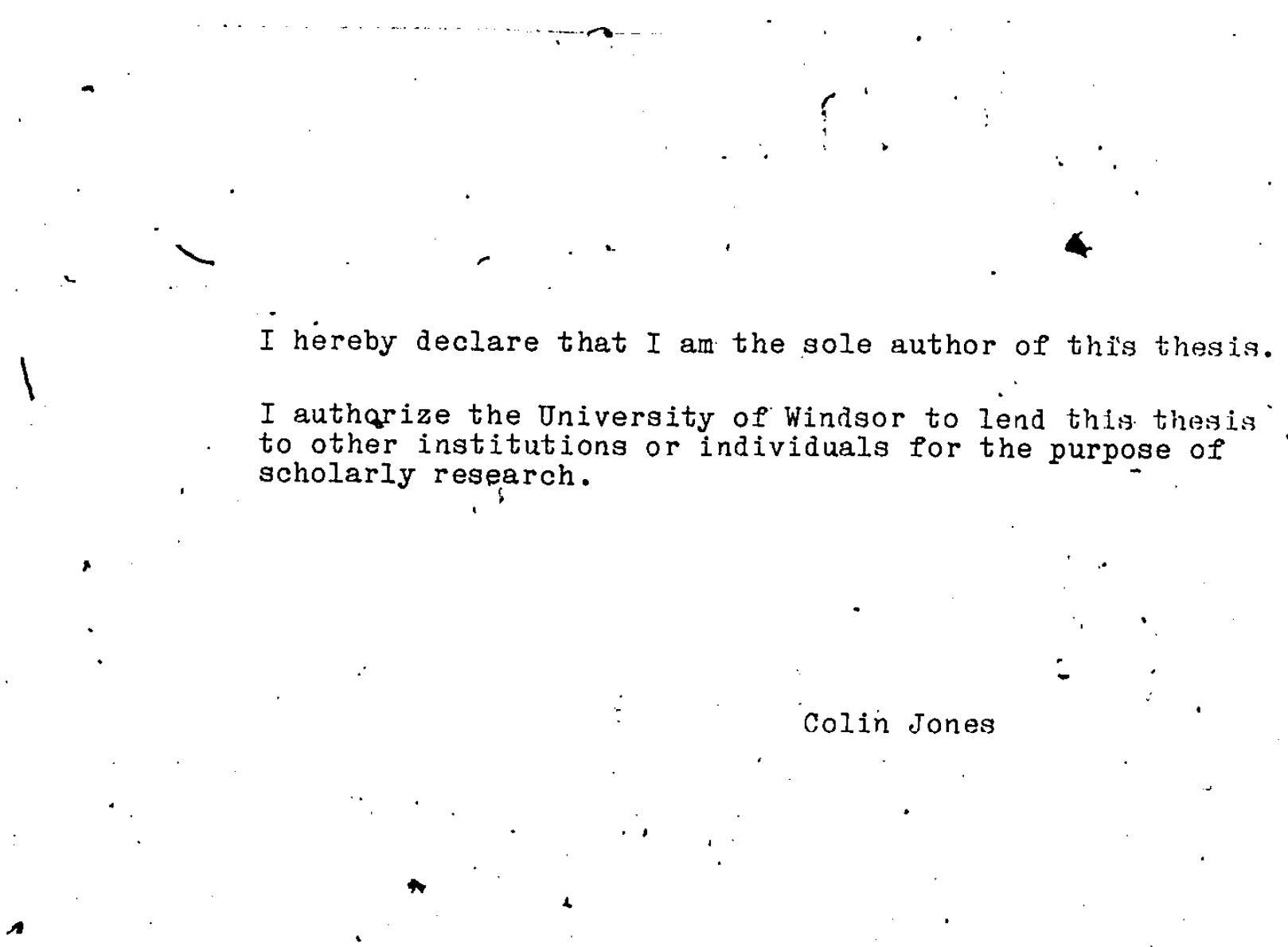

I further authorize the. University of Windsor to reproduce this thesis by photocopying or by other means, in total or in pirt, it the request of other institutions or individuals - Cor the purpose of scholarly research.

\section{Colin Jones}




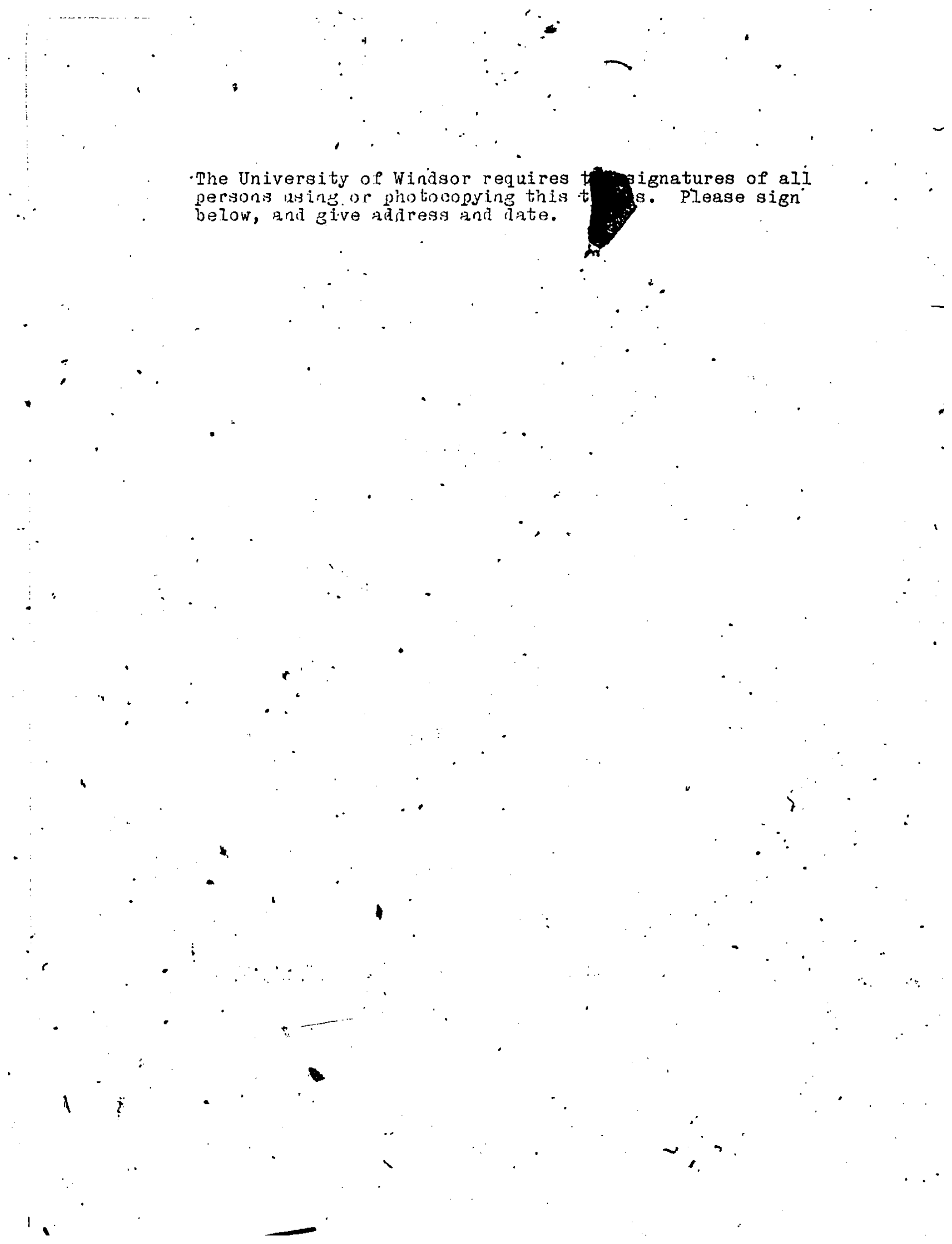


ABSTRACT

The main purpose of the study was to investigate the relationship between locus of control, assertiveness, and anxiety, on one side and headache frequency and severity, on the other. Information concerning headache incidence and type, precipitating factors, and other psychosoratic symptoms reported; was also provided. The data were । oltained by questionnaires (Rotter Locus of Control Scale (IC), Rathus Assertiveness Schedule (RAS), Health Locus of Control. Scale (HLC); and a Headache Questionnaire), which were completed by 222 introductory psychology students. A significant correlation was found between. anxiety and headache, but it was weaker than might be expected considering that headache is commonly viewed as. a physiological sign of anxiety. An explanation for this finding was offered, concerning how level of reportiel anxiety may bo moderated by the subject's assertiveness and locus of control. Subjects who were nore internal, inoreassertive and less anxious, yet reporter substantial headache activity, may have been denying their anxiety. Further research, asing a physiological measure of. anxiety, is needed to ald support to this explanation. The incidence of headache in the sample was similar to that found in other recent studies of the general. population, but higher than some studies of university populations. This was discussed, along with the clear sex differences that were found and sone other related issues. 


\section{$\checkmark$}

\section{ACKNOWLEDGEMENTS}

I want to thank the pollowing people for their valaable assiatance with lihis enderavir:

Dr. Stewart Page for showing a genuine interest in my topic, his very useful and workable sugyestions, generat. guilance and unflagging encolarageinent.

Dr. Neil Holland for his perceptive comments which helped ne put this study into its proper perspective. Dr. Dev Purushotham for a more medical view of my thesis and for her personal warmth.

Most of all I want to thank my wife kathy for the ' many hoúrs she spent typing my work, and for having the patience to decipher my enigmatic scrawt, and also for ‘ putting up with me, in general. My daughters, Debbie and, Della, have also given me a lot of support, and the three of them have helped me more than they could ever know, or I could ever tell. 


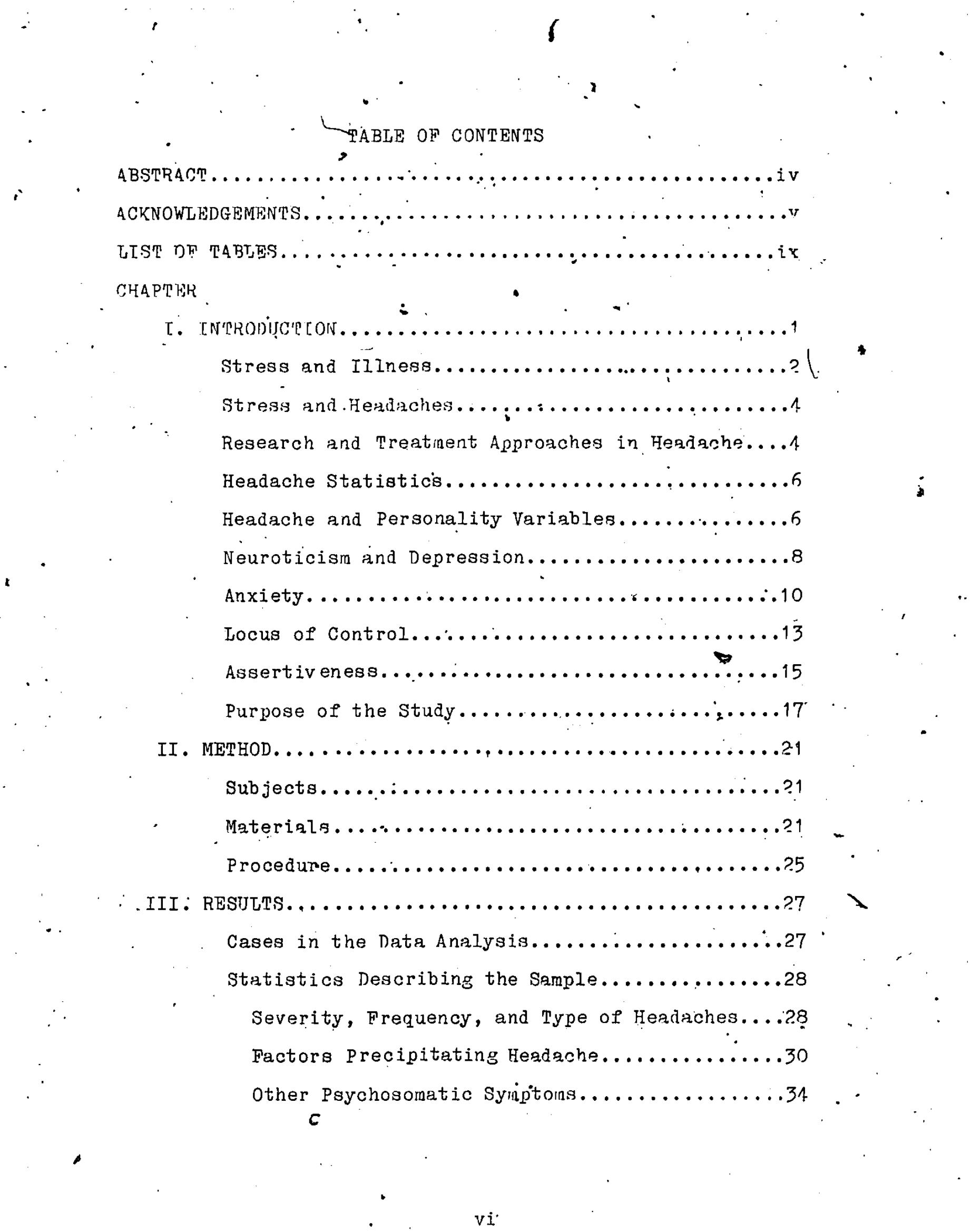




\section{)}

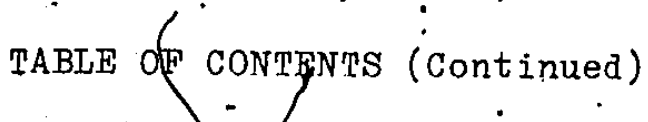

Relationship of the Rersonality Variables

to Headache...............................

Means, Standard Deviations, Minimum and

Maximun values..........................

Pearson Product-Moment Corṛelations.........ti

Chi-Square Tests..................45

Strident t Tests........................

Multiple Comparison Tests.............. . .

Resporse Frequencies for the Eight.

fombinations of the Dichotonized variables.

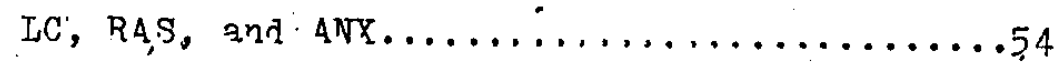

Multiple Regression Models............59

Other 4nzlygeq.....................61

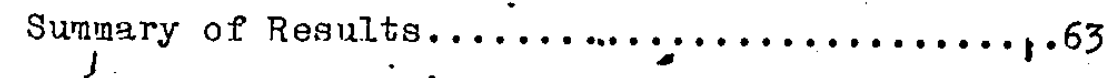

Results Describing the Sample.............63

Results Concerninf the Relationship of the

.Personality Variables to Headache............64

Relationship of IC to Headache..........54

Relation ship of RAS to Headache.........65

Relationship of ANX to Headache.........55

Relationship Between IC, RAS, and ANX.....66

Relationship of the Combinations of IC, RAS,

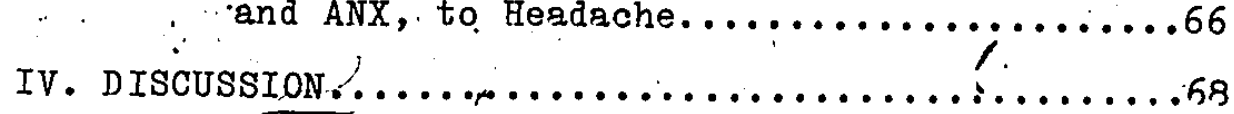

Relationship of the Personality Variables

to Headache......................... 68 
TABLE OF CONTENTS (Continued)

Jtility of the HLC in Headiche Regersch....73

Relationships Between the 16P Factors

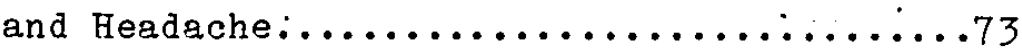

Relationship Retween, Sex. of the subjedt

and Headzche.......................... . . .

Summary.......................75

Findings Describing theSemple...........75

Headache Frequency and Severity........?5

- Headache Type.......................78

Precipitating Factors..............79

Dther Psychosomatic Symptoms..............

Suninary ..........................

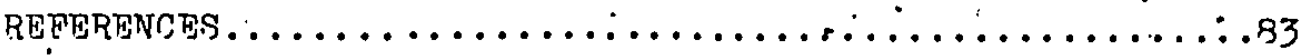

APPENDIX

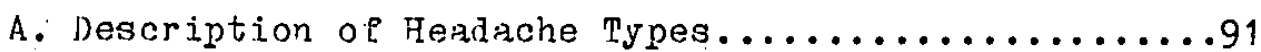

B. Health Locus gf Control seale......................

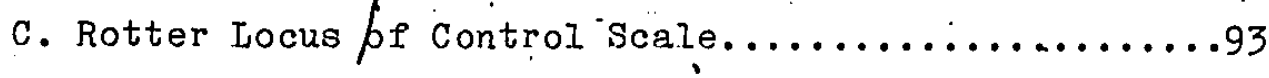

D. Rathus Assertiveness Schedule................95

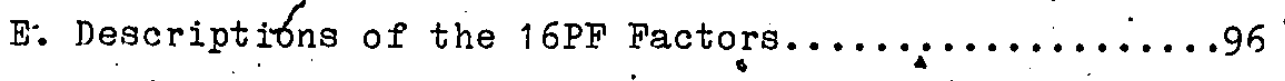

F. Headache Questionnaire....................

G. Median'splits for Fach of the Variables..........101

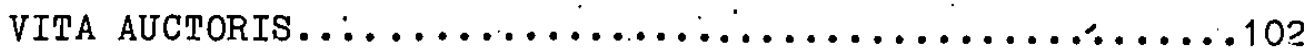

wiii
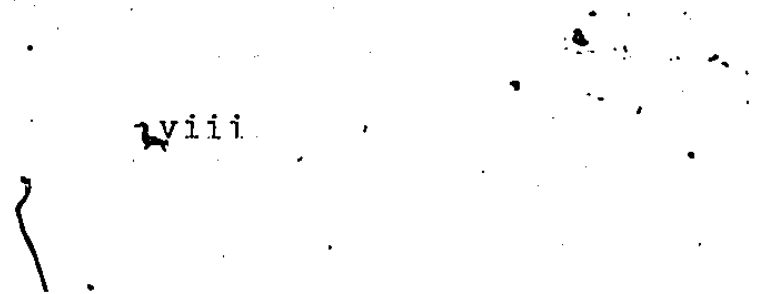


\section{IIST OF. TABTHS}

PAB B Bis

1. [ncidence of Headache as Reported in Selected.

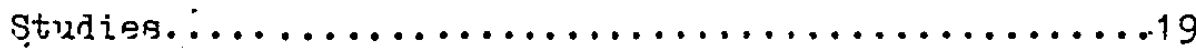

?. Listing of Dependent and Independent Variables.....20

3. Number and Percentage of Subjects Classified into:

A. Severity of Headaches, Showing Men and Women

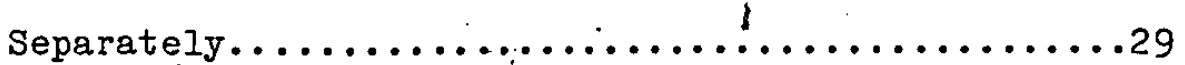

B. Frequency of Headache, Showing Men and Women

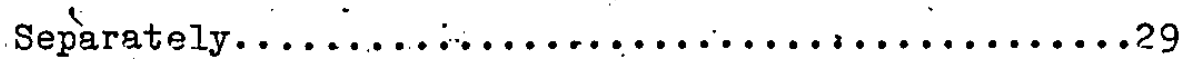

C. Types of Headaches, Showing Men and Women Separately.

4. Precipitating Factors by Rank Order, with Number of Times Listed.

A. Men and Women............................

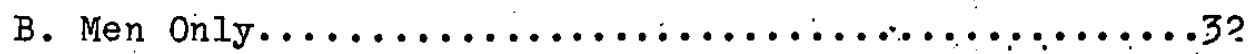

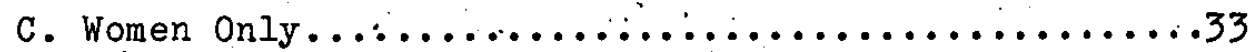

5. Number of Other Psychosomatic Symptoms Listed, Shown Separately for Men and Women Within Levels

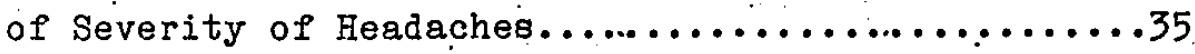

6. Comparịson of Means for Number of Psychosomatic Symptoms, By Levels of Severity of Headaches......36

7A.Means, Standard Deviations, and Minimum and

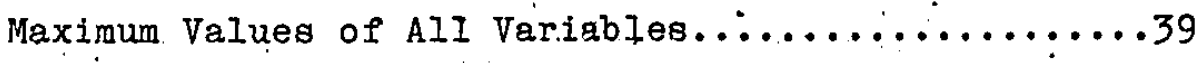

B.Means, Standard Deviations, and Minimum and Maximum Values of All Variables, Showing Men and

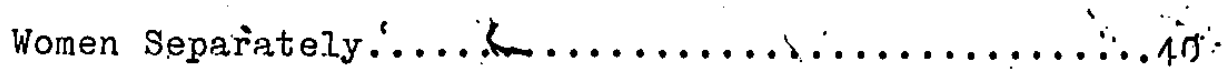
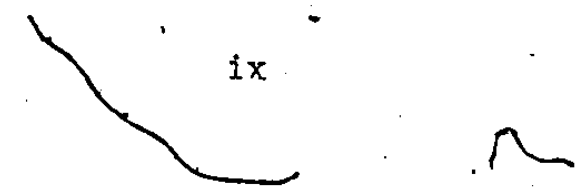


\section{LIST OF TABLFS (Continued)}

A. Purmu Proluct-Moment Correlations for Variables

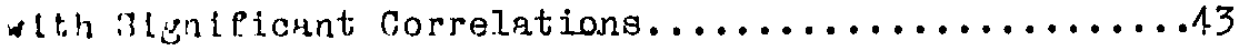

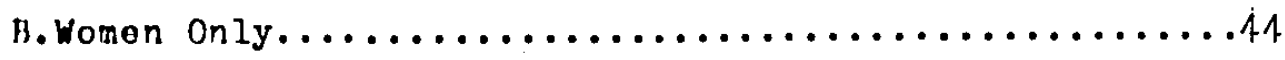

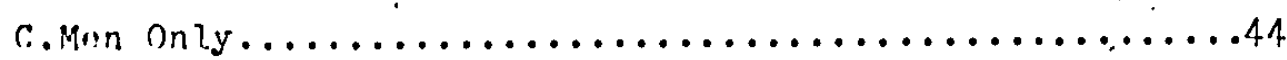

9. Ponrson Product-Moment Correlations for Variables

with Significant Correlations, for Weekly Headaches

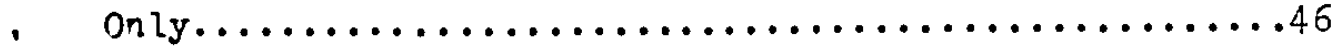

10. Ch1-Squares for Each of the Pairings of the ,

Dlchotonized Variables, LC, RAS, ANX, FREQ, and SEV...48

$\therefore$ 11. T Tests Showing Variables with Significant Differences

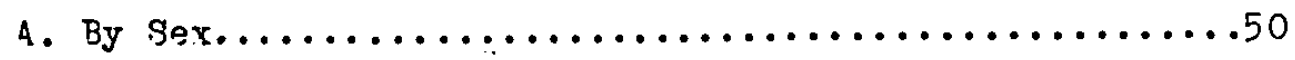

B. By Frequency of Headache, Dichotomized into Group 1 : No Headache, Less than Yearly, and Yearly Vs. Group 2 : Monthly and Weekly...........5n

C. By Severity, of Headache, Dichotomized into, -

Group 1 : No Headache Vs. Group 2 : Mild and

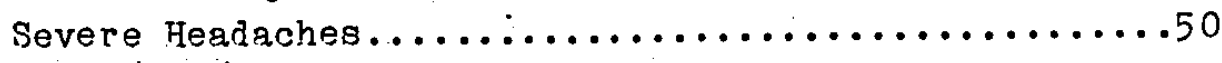

12. Tabie of Means for. FREQ and SEV by the Dichotonized

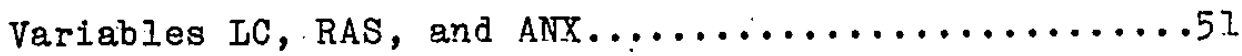

13. Means for FREQ, SEV, and ANX, for the Fight Combinations of the Dichotonized Variables

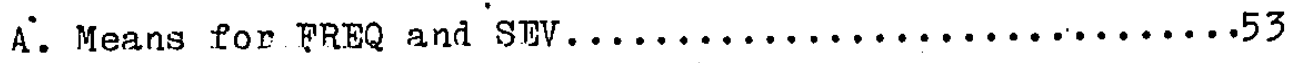

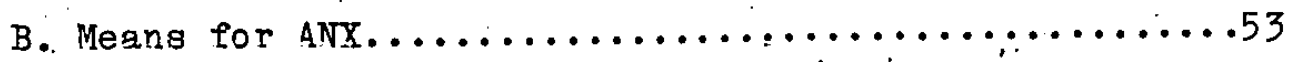

14. Response Frequencies (With Probabilities in Parentheses) for the Eight Combinations of the Dichotomized Variables IC, RAS, and ANX, By Frequency of Headaches.

\section{1}




\section{LIST OF TABLES (Continued)}

15. Response Frequencies (With Probabilities in

Parentheses) for the Eight Combinations of the

Dichotomized Variables LC, RAS, and ANX, By

Severity of Headache...................... 57

A. Group 1 Consists of No Headaches and Mild

Headaches : Group 2 Consists of Severe

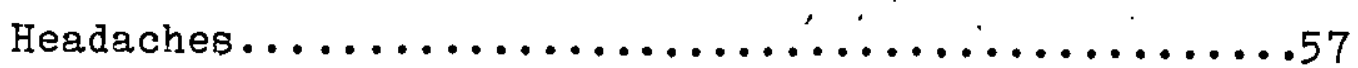

B. Group 1 Consists of No Headaches : Group 2

Consists of Mild and Severe Headaches............ 57

16. Response Frequencies (With Probabilities in.

Parentheses) for. the Eight Combinations of the

Dichotomized Variables, LC, RAS, and ANX, Showing

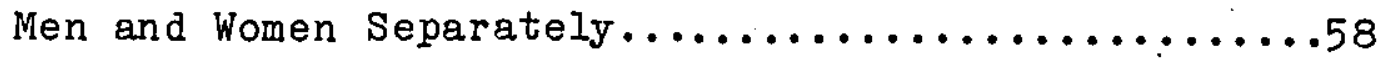

A. By Severity of Headaches. Group 1 Consists of

No Headaches : Group 2 Consists of Mild and

Severe Headaches........................ 58

B. By Frequency of Headaches. Group 1 Consists of

No Headaches, Less than Yearly and Yearly:

Headaches : Group 2 Consists of Monthly and

Weekily Headaches.........................58

17. Summary Table for the Multiple Regression

Analysis Showing the Relationahip of SEX, ANX, LC,

and RAS to Headeche Frequency................60

13. Sumary Table for the Multiple Regression

Analysis Showing the Relationship of LC, RAs, ANX,

and SEX to Headache Severity, for Weekly

Headiches only: 


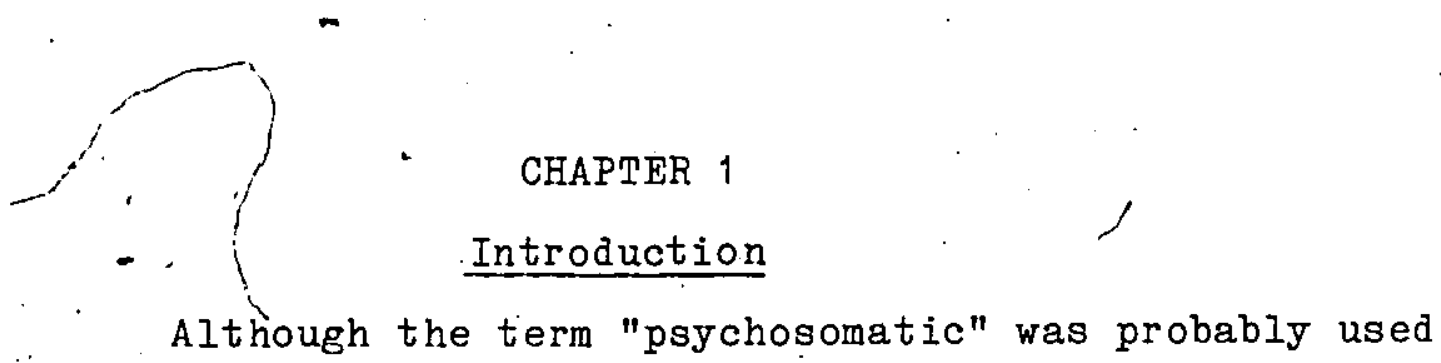
first more than one hundred years ago (Weiss \& English, 1957); it has only come into common usage within about the last 50 years. Psychosomatic is most often used to refer to those disorders whose, "etiology at least in part is believed to be related to emotional factors;" (Hinsie \& Campbeil, 1970, p.628). In itself; the word is rather misleading, implying a dualism between mind and body which does not exist. No physical disprder is completely free of psychological. factors, just as psychiatric disorders must always contain some organic component or constitutional factor. However certain disorders, such as organic heart disease, functional and nervous system disorders, appear to contain a significant psychological component and are generally considered within the realm of psychosomatic medicine (Weiss \& English, 1957). Many researchers have shown a high prevalence of psychological problems in those seeking medical care (Matarazzo \& Carmody, 1983). Bakal (1979)

- has concluded that 60 to 90 percent of general health problems have an important psychological component and this underlines the great importance of this area of investigation. Even more recently the biopsychosocial - perspective has postulated that psychosocial factors are

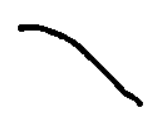


involved in all illnesses, "because illness occurs in individuals, who have not only a biological make-up but a psychological and social make-up as wèl." (Matarazzo \& Carmody, 1983, p.659). This latest advance in psychosomatic medicine therefore recognizes the role that - one's social environment plays in iliness. . Stress and IIIness

Hans Selye (1956) has long recognized that a person's environment may be perceived by him as a source of stress and that this can lead to mental or physical. illness, or both. Selye described 31 "signs of danger" and put forward the hypothesis that "each of us tends to respond particularly with one set of signs, caused by the malfunction of whatever happens to be the most vunerable part in our machinery..." (Selye, 1956, p.174). These. : "indexes of stress" included the now well-accepted symptoms of psychosomatic disorders, such as gastro-intestinal and sleep disorders as well as migraine headaches, and depressive or emotional reactions. However, at present, the concept of stress is too wide to be of real value in the investigation of the antecodents of psychosomatic disorders, and therefore it neéds to be' defined more precisely and narrowly (Steptoe, 1980). A very large amount of reaearch has centered around the relationship of stressful life events to psychiatric. and physical disorders. However, as David Mechanic 

likely that most of the general population is exposed to similarly stressful life events and therefore the critical factor may be the individual's method of coping with such stresses.

\section{Stress and Headaches}

One area which employs stress management as a treatment technique is that of headache. This approach is based on the assumption that headaches are the outcome of some kind of cognitiva response to stressful. situations. Accepting this widely held assumption suggests that headache may be used as a physiological measure of stress. However, it seems unlikely that this assumption would apply to cases of organic headache, that is those caused by brain tunours or other serious disorders. As the Ad Hoc Committee on Classification of Headache (1962) has sṭated, only migraine, tension, combined, and psychogenic headaches are considered to be related to stress. (See Appendix A for headache types). Research and Treatment Approaches in Headache

- Currently there are four research and treatment approaches to the problem of headache (Sargent, 1982). 1. Psychoanalytical. Research has tended to concentrate on migraine rather than tension headaches. Traditionally the migrainous individual has been described as tense, hard driving, and having difficulty in coping with stress (Wolff, 1963). The psychoanalytic concept sees the 
migraineur as repressing $h$ is hostility or anger, an issue which is also. cominon to many other psychosomatic disorders. In a review of the literature concerning migraine headaches, Bakal (1975) found several studies in which the expression of hostility and competition appeared to trigger the onset of headache in migraineurs. However Bakal also found other studies which showed inconsistences and he concluded that the idea of a definite migrainous personality was not completely convincing.

2. Pharmacophysiological. Migraine headaches have been shown, by various researchers (see Sargent, 1982), to be due to disturbances, of the cranial vasculature. What triggers the constrictions and dilations of these blood vessels is not completely understood but may involve the production of certain chemicals, possibly endorphins (Reed, 1980). In tension and psychogenic headaches, researchers have not found a significant reduction in. cerebral blood flow (see Sargent, 1982). 3. Behavioral Therapy. With both migraine and tension headaches the relaxation response has been found to be useful in reducing headaches, as have cognitive coping skills and assertiveness training (see Sargent, 1982). These successes, though limited, strongly suggest a cognitive component to headache, in addition to the muscular tomion involved. 
4. Psychophysiological. This approach has investigated the use of self-regulation techniques, 'such as biqfeedback, to control headaches. These techniques have been used with both rigraine and tension headaches, with some success. Although useful as a treatment technique, this approach adds little to our knowledge about the etiology of headache.

Headache Statistics

For such a common compleint it is surprising how little statistical information is available on the incidence.and prevalence of headaches in the general population. As far back as the fate 1940s, H.D.Ogden (Ogden, 1952 noted this and set out to study headaches in various occupational groups in New Orleans. Ogden found 64.8 percent of his sample suffered from some form of headache and that its incidence tended to be greater in women, younger adults, single people, educated individuals, professional and executive groups, and students. Studies into the incidence of headache have provided estimates ranging fróm 47 percent in a j. $\bar{s} . A$. college student population (Hicks \& Kilcourse, 1983) to approximately $84^{\circ}$ percent in a general population in a North American city (Ziegler, Hassanein, \& Couch, 2977), (See Table 1 for a sumary of selected studies). Headache and Personality Variables

There lis no doubt as to the pervasiveness of 
headache throughout the population of the world. It cuts across all occupations, socio-economic levels, races, creeds, and ages. However there seems to be fairly strong evidence for believing that women tend to experience nore headache, overall, than men. (See Table 1). There is. - weaker and less conclusive evidence concerning the role of personality variables in headache, although this area would appear to have great potential for understanding and therefore treating headache. As Martin (1983) points out, there has been a lot of attention paid by clinicians to the question of why one individual suffers from a particular problem while another Individual does not. Although Martin suggests that the search for antecedents would be a better way to understand headache mechanisms, we still do not have a clear idea about the first quegtion. Df course it would add greatly. to our. knowledge of headaches and be especially useful for prevention, if an individual could predict (and therefore avoid) situations or stimuli that could precipitate his ar her headache. However such knowledge would be facizitated by first being aware of which psychological or personality features interact with the stressful stition to produce a headache. Also there are very many "triggers" for headaches. For example, fatigue, heat, hunger, allergic reactions, excitement, menstruation, constipation, eye strain, and hypertension, 
just to name a few. Certainly investigation of the individual's own headache triggerssofould be of great benefit to him or her, but it is hardly feasible to. consider investigating each and every' case of headache scientifically. It is possible that idipsyncratic responses to stress nay be the only valid way to underptand headaches, but at this time the search for a more general aspect of personality or psychological

" Punctioning should not be abandoned.

- Several specific personality characteristics of headache sufferers have been cited as being related to headache activity. In particular the roles of neuroticism, depression, and anxiety have been examined. Neuroticism and Depression

Huber', Hubert, and Herper, (1982) investigated whether long-term migraine patients differed from a psychosomatic reference group or a healthy control group, in terms of personality characteristics and physiological responses to stress. They found that the migraineurs received the highest scores on the neurotic triad (Hypochondriasis, Depression, and Hysteria) of the Minnesota Multiphasic Personality Inventory (MMPI). The psychosomatic group was second and the control group of normals, third. These differences were all statistically significant. They also found that the three groups differed significantly in their physiological responses 
$\int_{\text {to sfress, although this pattern was not clear. Huber et }}$ (females with long-term migraine), it may not be representative of the general population of headache sufferers. However Waters and $0^{\prime}$ Connor (1970) had also found headache patients more neurotic than controls. Using the Cornell Medical Index as a measure, they

- further reported no significant differences in neuroticism between migrainous and other headache patients.

Cuypers, Altenkirch, and Bunge (1981) also found no sifnificant differences in neuroticism (using the Freiburg Personality Inventory), between groups of patients having migraine and cluster headaches (vascular type headaches which occur in bunches). However they further reported no indication of neuroticism in either group. Ajwani and Ajwant (1983) found significantly higher anxiety and depression scores (using the MMPI and an Anxiety Scale), in 130 headache sufferers compared to controls who were without a headache for one year. They too found no significant differences between tension and migraine headache sufferers on anxiety and depression scores.

Another recent.study (Garvey, Schaffer \& Tuasion, 1983) demonstrated the relationship between headache and depression without relying on self-report inventories or 
questionnaires. Patients who were diagnosed as having major depressive disorders kept daily recordings of headache frequency and were found to have an increased rate of headache whon compared to a non-depressed control group.

It seems then that some evidence exists to support the hypothesis that neuroticism and depression have some kind of relationship to headache. However the role of. anxiety is less clear and could stand further scrutriny. Anxiety

Anxiety has been defined in may different ways with most definitions pointing out that it is a pervasive feeling of dread, characteristic of many, neuroses. It is also. well accepted that anxiety has, at least, two sides; the psychological and the physiological. (The behavioral side of anxiety is not considered relevant to this discussion). Measuring the psychological element has proved to be rather difficult and is usually attempted by behavioral observation and self-reports. The physiological element appears more amenable to measurement, with increased heart activity, plushing and perspiration, increased respiration, and gastro-intestinal disturbances being considered anxiety indicators (Weiss \& English, 1957). It is not unreasonable then to assume that headache activity may also represent a somatic element of anxiety. Tension is 


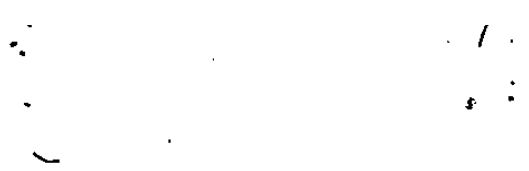

considered to be both an element of anxiety and of headaches, not only of the tension type, but also of migraine (Tfelt-Hansen, Lous, \& Olsen, 1981). İt should be recognized that "tension" may be intended to rẹfer more to muscle tension when speaking about headaches, while it refers more to a kind of emotional strain, when speaking of anxiety. However, as muscular tension is ( often assumed to be due, under appropriate circumstances, to mental or emotional strain, the two do appear to be related.

A great problem in research involving anxiety is. whether the measuring instrument is valid. Anxiety is a complex enofional state, having many different components. In order to lend support to claims that their particular instrument does in fact measure anxiety, many researchers have sought criterion validity. One such measure is the anxiety "second order factor" of Raymond Cattell's Sixteen Personality Factor (I6PF) Questionnaire (Cattell \& Eber, 1962). In this very well established self-repprt inventory, anxiety is seen as a pattern of . the. scores obtained in emotional stability, threat sensitivity, suspiciousness, guilt, Iow "integration, and tension, plus several,other scores varying with the sex of the subject. (Krug, 1981). This pattern of scores has been 'shown to be strongly correlated with criterion measures of anxiety (Krug, Scheier, \& Cattell, 1976). On 
the other hild, the empirical criterion keying approach of the MMPI selects items to be included in various' scales by virtue of their power to discriminate between groups. The I6PF then, may be a more appropriate method for measuring anxiety, at least in a non-psychiatric population, as it was standardized using a "normal". pollation and is correlated with other anxiety measures: In order ta avoid the problems inherent in a one-time assessment questionnaire (e.g. memory and reporting bias, as previously discussed), Arena, Blanchard, and Andrasik, (1984) used rating scales completed daily, one of which was used to rate anxiety from "not at all anxious" to "as anxious as ever been:" Subjects also completed the Speilberger State-Trait. Anxiety Inventory (STAI) and rated their headache activity four times a day on a six pointe scale, from 0 : (no headache) to 5 (intense, incapacitating headache). Only a weak relationship was found between headache and anxiety (and the two other affects, anger and depression). The authors concluded that their findings, "cast serious doubt"upon many psychological theories regarding the etiology of headache and on the relationship between affect and headache in general". (Arena et al., 1984, p.l). However the atudj did show some relationship between 'anxiety and headache and it does seem that headache oluferers may tend to report a little more anxiety; thamnon-headache sufferers. $\because$ 
In a study comparing the State-Trait. Anxiety Inventory (STAI) scores and galvanic skin responses (GSR) of anxious neurotics, tension headache sufferers, and normals, Chattopadkyay and Mazumber (1982) reported a very interesting finding. On the physiologic measure (GSR), both the neurotics and headache patients had similar levels of arousal to a stressful stimulus, but on. the, self-report measure (STAI) the anxious neurotics had higher scores. It may be then that tension headache sufferers do not report excessive anxiety but do havefairly high physiologic signs of anxiety.

This finding suggests that there may be some other personality variables which moderate the way headache sufferers cope with stress and with anxiety. The individual's locus of control (Rotter, 1966), and level of assertiveness, may be two possibilies fof such variabîes.

Iocus of Control

The basic purpose behind Rotter's Locus of Cantrol Scale is to assess an individual's generalized expectancies for reinforcement (Rotter, 1966). The scale items sample locus of control orientation over a variety of situations and contexts. Internal control "attributes agency to oneself, a coping procedure, whereas external control gives agency to others or to fate" (Haan, 1982, p. 
Lefcourt (1981) proposed that "locus of control ineasures can operate as moderator variables in the prediction of responses made to life stressors. Those persons who were more external... were more likely to report distress associated with negative life events." (p.269). Along these same lines, other researchers, (Ray \& Katahn; 1968; Watson, 1967) reported that the more external the individual's locus of control (as measured by Rotter's Iocus of Control Scale), the more anxiety is reported. However, Houston (1972) (also using the Rotter Locus of Control Scale) found that internal-control and external-control subjects did not differ in reporting anxiety in stressful situations. Houston did report Though that internal-control subjects became more physiologically aroused (as measured by a change in heart rate) than external-control subjects, when in stressful situations. Research since.Houston's study has tended to support the hypothesis that those with a more external' locus of control, will report more anxiety (e.g. Carter, 1983; Lefcourt, 198I), and this finding is now commonly accepted..

Houston's finding that internal-control subjects becomefinore physiologically aroused when under atreas, underiines the dual elemelsts of anxiety discussed earlier. It may be that "internalizers" (internal-control subjects) although reporting less 
anxiety than "externalizers" (external-control subjects) become more physiologically aroused when experiencing stress. Internalizers may believe that they have more control over stressful life events and therefore will tend to view those situations as less threatening and less anxiety arousing (Lazarus, 1966). It may also be the case that internalizers are reluctant to admit to anxiety and it is therefore expressed somatically. One way this could occur is through headaches, or through other psychosomatic disorders. It seems that - externalizers are morelikely to report anxiety, and as this is a way to release feelings, any physiological symptoms of anxiety that they may have, might be dissipated somewhat:

Assertiveness

Related to this theory, that headache sufferers may have difficulty in expressing emotions, is the "traditional" belief that unassertiveness is a personality trait of such patients. Anxiety has al:30 been linked to unassertiveness and research has shown that assertiveness training may reduce anxiety levels in ulcer patients (Brooks \& Richardson, 1980). Waksman, (1984) also found that after assertiveness training, adolescents had reduced anxiety and scored more in the internal-ciontrol direction on a locus of control measure. $\therefore \quad$ However, in headache research, assertiveness does not 
seem to have been a major area of investigation. Recently though, a group of researahers (Andrasik, Blanchard, Arena, Teders, Teevan, \& Rodichok, 1982) conducted a study to investigate the relationship of several personality variables to headache including assertiveness (using the Rathus Assertiveness Schedule, (RAS)). They found no significant relationship between assertiveness and headache using chronic, severe headache patients as subjects. . Although it would seem likely that any personality traits (such as unassertiveness) would be more exaggerated in such a group, these patients may not be representative of headache sufferers in general. However Andrasik et al clained that, as their sidjects showed less overall "psychological disturbance" than other headache patients, their results may be more representative of typical headache sufferers. Another possible difficulty with this study involved the control group which contained subjects who could have up to six headaches per year, none of which could be "problematic". How "problematic" was objectively defined is not specified and this word may have been interpreted differently by individual subjects, resulting in the inclusion of headache sufferers in the control group. In sumnary it appears that the relationship between unassertiveness and headache could be clarified by further investigation, particularly in noh-patient 
populations.

\section{Purpose of the Study}

Bearing in mind the assumption that the majority of people are subjected to a similar amount of stressful Iife events during their licetine, the present study examined the relationship between locus of control, assertiveness, and anxiety, as factors in stress related headaches. In particular the study was designed to determine whether specific combinations of these personality variables (e.g. more internal, less assertive, and less anxious), would be useful in predicting or discriminating between severity and/or frequency of headaches. As the entire 16PF Questionnaire was administered, other "second order factors" as well as the individual scales were also scrutinized for possible relationships with headache frequency or severity.

In addition to using a measure of generalized locus of control (Rotter's Scale) a measure specifically designed to assess locus of control in regard to health matters was also used - the Health Locus of Control Scale . (Wallston, Wallston, Kaplan, \& Maides, 1976). The bassis of this scale is that those scoring in a more external direction generally believe that they have little control over the Pactors determining their health, whereas those scoring more internally tend to believe that their" own behavior determines whether they remain healthy or become 
ill. (Wallston \& Wallston, 1981). The relationship of both these locus of control scales to headache can then be compared with a view to determining whether goal-specific measures, like the HLC, are more useful than generalized measures, in certain situations. The study also provided various descriptive statistics, including frequency, severity and type of headache; ranking of factors which precipitate headache; and number of other psychosomatic symptoms.

Table 2. lists the dependent and independent variables, and covariates, which were employed in the study. . 
Table 1

Incidence of Headache as Reported in Selected Studies

\begin{tabular}{|c|c|c|}
\hline $\begin{array}{l}\text { Author (s), Year, } \\
\text { and place }\end{array}$ & $\begin{array}{l}\text { Size and Type } \\
\text { of Population } \\
\end{array}$ & $\begin{array}{c}\text { Reported Incidence } \\
\text { of Headaches }\end{array}$ \\
\hline $\begin{array}{l}\text { Ogden, } 1952 \\
\text { New York, U.S.A. }\end{array}$ & $\begin{array}{l}4,634 \text { stratified } \\
\text { in occupational } \\
\text { groups }\end{array}$ & $\begin{array}{l}64.88 \text { total } \\
50.78 \text { men } \\
71.08 \text { women }\end{array}$ \\
\hline $\begin{array}{l}\text { Brewis, Poskanzer } \\
\text { Rolland, \& Mïller } \\
\text { 1966. Carlisle, } \\
\text { U.K. }\end{array}$ & $\begin{array}{l}6,960 \\
\text { General } \\
\text { population } \\
\text { sample }\end{array}$ & $\begin{array}{l}\text { Disabling } \\
\text { headaches only. } \\
6.28 \text { total } \\
4.18 \text { men } \\
8.18 \text { women }\end{array}$ \\
\hline $\begin{array}{l}\text { Waters, } 1974 . \\
\text { Pontypridd, U.K. }\end{array}$ & $\begin{array}{l}1,718 \\
\text { Random sample of } \\
\text { population }\end{array}$ & $\begin{array}{l}71.78 \text { total } \\
63.58 \text { men } \\
78.48 \text { women } \\
\end{array}$ \\
\hline $\begin{array}{l}\text { Waters, \& } \\
\text { O'Connor, } 1975 . \\
\text { U.K. } \\
.\end{array}$ & $\begin{array}{l}4,214 \\
\text { Random sample } \\
\text { and two groups } \\
\text { of medical } \\
\text { patients }\end{array}$ & $\begin{array}{l}\text { Migraine only } \\
19 \text { to } 24.58 \text { total } \\
15 \text { to } 208 \text { men } \\
23 \text { to } 298 \text { women }\end{array}$ \\
\hline $\begin{array}{l}\text { Ziegler, } \\
\text { Hassanein, \& } \\
\text { Couch, 1977. } \\
\text { U.S.A. }\end{array}$ & $\begin{array}{l}1,809 \\
\text { religious, civil } \\
\text { and professional } \\
\text { groups }\end{array}$ & $\begin{array}{l}83.78 \text { total } \\
82.68 \text { men } \\
84.28 \text { women }\end{array}$ \\
\hline $\begin{array}{l}\text { Hicks \& } \\
\text { Kilcourse, } 1983 . \\
\text { Sán Jose, U.S.A. }\end{array}$ & $\begin{array}{l}176 \\
\text { College students }\end{array}$ & $\begin{array}{l}478 \text { total } \\
\text { (no other } \\
\text { figures } \\
\text { available }\end{array}$ \\
\hline $\begin{array}{l}\text { Hicks \& Campbell } \\
\text { 1983. San Jose, } \\
\text { U.S.A. }\end{array}$ & $\begin{array}{l}177 \\
\text { College students }\end{array}$ & $\begin{array}{l}478 \text { total } \\
\text { (no other } \\
\text { figures } \\
\text { available }\end{array}$ \\
\hline $\begin{array}{l}\text { Ogunyemi, } 1984 . \\
\text { Nigeria, Africa. }\end{array}$ & $\begin{array}{l}1,756 \\
\text { College students }\end{array}$ & $\begin{array}{l}59.58 \text { total } \\
58.98 \text { men } \\
60.78 \text { women } \\
\end{array}$ \\
\hline
\end{tabular}


Table 2.

Listing of Dependent and Independent variables

Depèndent Variables

1. Frequency of headache : Five levels - nil, less than one per year, yearly, monthly, and weekly.

2. Severity of headache : four levels - nil, mild, severe, and disabiing.

Independent Variables

1. Health Locus of Control (HLC) : range of possible scores 11 to 66 .

2. Rotter Locus of ControI (LC) : range of possible scores 0 to 23 .

3. Rathus Assertiveness Schedule (RAS) : range of possible scores -7 to +107 .

4. Sixteen Personality Factor (16PF) Questionnaire : range of possible scores 1 to 10 (First order), 10 to 100 (second order). Covariates/Independent Variables

1. Sex of subject.

2. Type of headache : four levels - nil, migraine (including cluster), combined, and tension. 
CHAPTER 11

Method

Subjects

There were a total of 222 subjects, 69 men and 153 women, all students drawn from introductory psychology classes at the University of Windsor. Age range of the sample was 17 years tor 51 years, with a mean of 20.4 years and a standard deviation of 4.3 years. The modal age was 19 years (for $49 \%$ of the subjects) and only 14 subjects (approx 6\%) were over 25 years. For most of the statistical analyses, 27 sets of scores were discarded either because the subject had identified his or her headache as "disabling" (II cases), or the case was identified as an "outlier" on one or more of the variables (12 cases), or the questionnaires were incomplete ( 4 cases). (See Results section for further details on these deletions). For the 195 subjects . remaining, the age range and modal age were the same as for the original sample, but the mean became 20.3 years, the standard deviation 4.2 years and the number of subjects over age 25 years was reduced by two. Each student who participated received two points to be added to his or her final grade in introductory psychology. Materials

Five questionnaires were used in the study, presented to the subjects in the following order: 
I. Health Locus of Control (HIC) Scale. (Appendix B) This scale consists of 11 items, which are rated using a 6-point likert-type format.' The items are composed of statements measuring expectancies regarding locus of control related to health. Potential range of scores is 11 to 66 and the scale is scored in an external direction. The scale was shown to have discriminant validity, in contrast to Rotter's Iocus of Control Scale, when used to discriminate between groups seeking health information and groups in a weight reduction programme (Wallston et al, 1976). Wallston et al found a correlation of .33 ( $\mathrm{p}<.01)$ with Rotter's Locus of Control Scale, further demonstrating the HLC's discriminant validity.

2. The Rotter Locus of Control (IC) Scale (Appendix C). Introduced by Rotter (1966), this scale, developed from the James-Phares Locus of Control Scale, measures generalized expectancies for reinforcement. It consists of 29 true-false items, 6 of which are "filler" items designed. to disguise the purpose of the scale. The gcale is scored in the direction of external locus of control. and has a potential range of scores from 0 to 23 . It $\cdots$ provides a measure of expectancy acrosis many, varied situations and has been used in a great number of investigations.

3. The Rathus Assertiveness Schedule (RAS) (Appendix D). 
Developed by Rathus (1973), this scale measures assertiveness or "social boldness". The 19 item version of this scale was used, in which the items are scored on a 6-point Iikert-type format from -3 to +3 . Potential range of scores is -57 to +57 but, for the present study, to avoid negative scopes, a constant of 50 was added to each score making the potentiat. range -7 to +57 . (although the actual range for this sample turned out to be +3 to +96). The scale is scored in the direction of assertiveness. Rathus (1973) reports a test-retest - reliability of $\underline{r}=.78, \underline{p}<.01$ and criterion validities of between .33 and .62 , with $\mathrm{p}<.01$. Each of the 19 items used in the present study were shown to correlate. significantly with the total score (p s <.05 or <.01). 4. The Sixteen Personility Factor (16PF) Questionnaire. Appendix E provides descriptions of the first and second order factors of this inventory which consists of 187 items, each with a choice of three responses, designed to measure many of the basic human personality variables. Each subjects's raw scores are converted to s.tandard scores (stens) based on the appropriate norm. tables, for the 16 primary factors. The second order factors are computed by using various weights. of selected prinary factors (see Krug, 1981). For the present study the Forn $B$ version was administer and in order to 
retain the greater variability, the scores for the second order factors were not reduced to sten scores. Potential range of the scores, for each of the primary factors was 1 to 10, and for the second order factors, 10 to 100. However the range for the second order factors was exceeded in a few cases which occurred when the subject's pattern of sten scores was very extreme. As Catțell, Eber, and Tatsuoka (1970) explained, "best weights for estimation ... differ somewhat from one population or sample to another." (p. 126). The norm tables used were those for male and female coliege students.

5. A headache questionnaire was constructed (Appendix F), based on several questionnaires used previously in headache Thies (Arena, Blanchard, Andrasik, \& Dudek, 1982; Brewis et al, 1966; Ogden, 1952; Waters, 1974;

- Ziegler et al, 1977). The basic question was "Have you ever been subject to headache?" If the subject responded "Yes" then several further responses were required, intended to assist in determining the type of headache, its severity, frequency, possible antecedents, and changes since onset. If the subject responded "No" then no further information, other than the demographic information already provided, was required.

The headaches were classified into three types; migraine (including cluster), combined, and tension. The 
classification was based on the Headache symptom i Questionnair'e items of Arena et al. (1982), which were included in the present headache questionnaire. The classification was accomplished using the Discriminant Function Coefficients provided by Arena et al. Although accurate classification of only $68.42 \%$ of cases is claimed, this was considered acceptable for the present study as headache type was mainly used only as a covariate. To reduce the probability of including organically based headaches in the analysis of the relationships between the personality variables and the headache measures, headaches classified. as "disabling", by the subjects themselves, were deleted.

\section{Procedure}

Subjects were recruited using "sign-up" sheets and arrangements made for the questionnaires and scales to be completed in groups of 20 to 50 students. At the start. of each session the subjects were asked to carefully read the instructions, printed at the beginning of each of the scales and at the top of the first page of the headache questionnaire, before commencing. Instructions for completion of the I6PF were included separately. The subjects were advised that all responses would be treated confidentially and that nares were not required on the testing materials. Any subject requesting his or her individual results, for each of the four scales (HLC, IC, 
RAS, and (16PF) was provided with his or her raw scores and referred to the appropriate iiterature for interpretation.

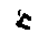

$\gamma$

1

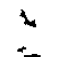

4

$!$ 


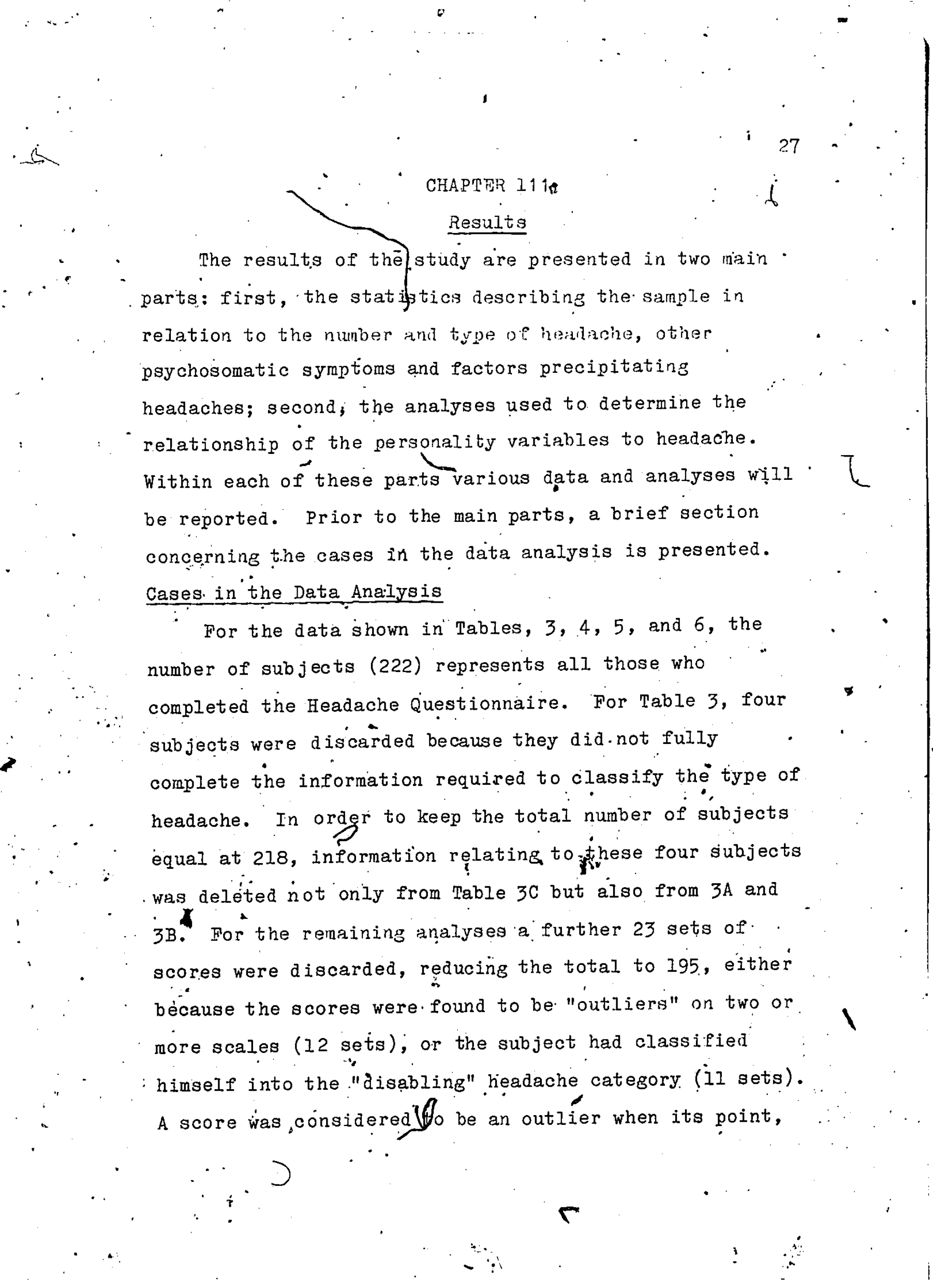


y as plotted by pairs of variables (e.g. IC by RAS or IC by ANX), was clearly discrepant with the majority of points on the scatter plot. (See Tabachnick \& Fidell, 1983). The "disabling" headache cases were discarded as they appeared to be the most. Iikely to contain severe, organically based headachęs, which were not considered relevant to this study.

All independent variables, were examined for normality and skewness of distribution, and found to be within acceptable limits be highly skewed, with severity and frequency midly skewed. However, as type of hexdache, frequency and severity 'were skewed in the expected direction (approx 80 percent of the sample reporting headache, with tension the most frequent type) transformations of the data were not . considered necessapy.

1. Statistics Describing the Sample

A. Severity, Frequency and Type of Headaches

Table 3 provides information about the severity, frequency, and type of hefdaches, both for the original 'sample and the sample after deletions were made, as described eatlier: The numbers and percentages are shown separately for men and women. Overall, approximately 82. percent reported experiencing headache, but. 27 percent of men reported "no headache" compared to 14 percent of women. Within the five levels of headache frequency, the 
Table 3 .

A. Number and Percentage of Subjects Classified into Severity of Headaches, Showing Men and Women Separately

\begin{tabular}{|c|c|c|c|c|c|c|}
\hline \multirow[b]{2}{*}{ Severity. } & \multicolumn{2}{|c|}{ Number } & \multicolumn{2}{|c|}{ Percentage } & \multirow[b]{2}{*}{ Tota1 } & \multirow[b]{2}{*}{ Percentage } \\
\hline & Men & Women & Men & Women & & \\
\hline $\begin{array}{l}\text { Nil. } \\
\text { Mild } \\
\text { Severe } \\
\text { Disabling }\end{array}$ & $\begin{array}{c}18(17) \\
22(21) \\
24(23) \\
3(0) \\
\end{array}$ & $\begin{array}{c}21(21) \\
62(60) \\
60(53) \\
8(0) \\
\end{array}$ & $\begin{array}{c}26.9(27.9) \\
32.8(34.4) \\
35.8(37.7) \\
4.5(0) \\
\end{array}$ & $\begin{array}{r}13.9(15.7) \\
41.1(44.8) \\
39.7(39.5) \\
5.3(0) \\
\end{array}$ & $\begin{array}{l}39(38) \\
84(81) \\
84(76) \\
11(0) \\
\end{array}$ & $\begin{array}{c}17.9(19.5) \\
38.5(41.5) \\
38.5(39.0) \\
5.0(0) \\
\end{array}$ \\
\hline ota & 67167 & 1113 & $100(100.0)$ & $100(100.0)$ & $218(19$ & $100.0)$ \\
\hline
\end{tabular}

B. Number and Percentage of Subjects Classified into Frequency of Headache, Showing Men and Women Separately

\begin{tabular}{|c|c|c|c|c|c|c|}
\hline \multirow{2}{*}{ Freguency } & \multicolumn{2}{|c|}{ Number : } & \multicolumn{2}{|c|}{ ·Percentage } & \multirow[b]{2}{*}{ Total } & \multirow[b]{2}{*}{ Percentage } \\
\hline & Men & Women & Men & Women & & \\
\hline & $18(17)$ & $21(21)$ & $26.9(27.9)$ & $13.9(15.7)$ & $39(3)$ & $17.9(19.5)$ \\
\hline $\begin{array}{l}\text { Less th } \\
\text { Yearly }\end{array}$ & $I(1)$ & $2(2)$ & $1.5(1.6)$ & $1.3(1.5)$ & $3(3)$ & $1.4(1.5)$ \\
\hline $\begin{array}{l}\text { Yearly } \\
\text { Monthly } \\
\text { Weekly }\end{array}$ & $\begin{array}{r}9(8) \\
26(24) \\
13(11) \\
\end{array}$ & $\begin{array}{l}17(16) \\
55(47) \\
56(48) \\
\end{array}$ & $\begin{array}{l}13.4(13.1) \\
38.8(39.3) \\
19.4(18.0)\end{array}$ & $\begin{array}{l}11.3(11.9) \\
36.4(35.1) \\
37.1(35.8)\end{array}$ & $\begin{array}{l}26(24) \\
81(71) \\
69(59) \\
\end{array}$ & $\begin{array}{l}11.9(12.3) \\
37.1(36.4) \\
31.7(30.3)\end{array}$ \\
\hline Totals & $67(61)$ & $151(134)$ & $100(100)$ & $100(100)$ & $218(195$ & 5) $100.0(100.0)$ \\
\hline
\end{tabular}

C. Number and Percentage of Subjects classified into Types of Headaches, Showing Men and women Separately

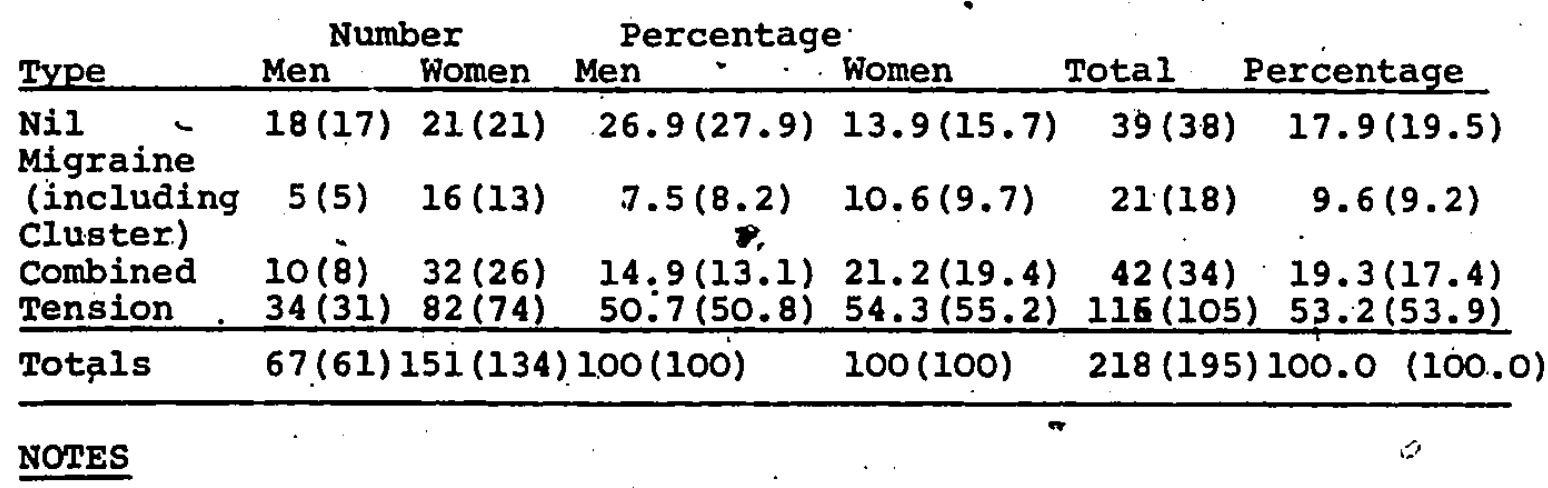

1. Numbers in parentheses represent the sample size after outliers and disabling headaches were deleted, with the corresponding percentages.

2. Some percentages may not sum exactly to 100 due to rounding. 
largest number of men and women reported monthly headaches (approximately 37 percent), closely followed by.'. those reporting weekly headaches (approximately 32 percent). Within this category (weekly headaches), are 37.1 percent of the fenale subjects, compared to 19.4 percent of the men. According to Table $3 \mathrm{C}$, the majority of the subjects (approximately 53 percent) suffered from tension headaches, with combined headaches and migraine headaches ranking second and third. However as the method uséd to classify the headaches is only 68 percent accurate (see "Method" section), these statistics may therefore be misleading and no weight is placed on them. B. Factors Precipitating Headache

The ranking of the factors thought to precipitate headaches is shown for men and women combined and for men and women separately, in Tables 4A, B, and C. Clearly considered to be the most important factors are."Mental Stress" and "Mental and/or Physical Exhaustion", both chosen by 79.7 percent of men and women. Overall, 86.4 percent of women indicated that they considered mental stress to be the most likely to precipitate headaches, while 76 percent:of men chose mental and/or physical exhaustion. "Too little sleep" was chosen as a precipitating factor by 77.5 percent of the men and women, making it the next most popular choice. On average, women chose 6.05 of the factors each out of 18 
Table 4

Precipitating Factors by Rank Order, with Number of Times Listed

A. Men and Women $\left(n=-182^{\mathrm{a}}\right)$

\begin{tabular}{lcc}
\multicolumn{1}{c}{ Factor } & $\begin{array}{c}\text { Number of } \\
\text { Times Iisted }\end{array}$ & $\begin{array}{c}\text { Percentage } \\
\text { of Subjects }\end{array}$ \\
\hline Mental stress e.g. Anxiety or Worry & 145 & 79.7 \\
Mental and/or Physical Exhaustion & 145 & 79.7 \\
Too Little sleep & 141 & 77.5 \\
Eyestrain & 99 & 54.4 \\
Hunger & 95 & 52.2 \\
Menstruation & 72 & 39.6 \\
Alcohol andior Drugs & 62 & 34.1 \\
Heat & 60 & 33.0 \\
Smoking & 4.7 & 25.8 \\
Too Much Sleep & 45 & 24.7 \\
Certain Foods & 31 & 17.0 \\
Hypertension & 0 & 16.5 \\
Exercise & 30 & 13.7 \\
Excitement & 25 & 12.6 \\
Unknown & 23 & 11.0 \\
Flashing Light & 20 & 9.9 \\
Other & 18 & 4.4 \\
Constipation & 8 & 2.7
\end{tabular}




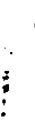

Table 4

B. Men only $\left(n=50^{a}\right)$

Factor

Number Times Listed

Percentage of Subjects

Mental and/or Physical Exhaustion

38

76.0

Too Little sleep

Eyestrain

32

64.0

32

64.0

Mental Stress e.g. Anxiety or Worry

31.

62.0

Hunger

24

48.0

Heat

21

42.0

Alcohol and/or Drugs

21

42.0

Too Much Sleep

11

22.0

Smoking

10

20.0

Exercise

Excitement

Certain Foods

10

20.0

Hypertension

Unknown

Flashing Light

Other

Constipation

9

7

18.0

6

14.0

6

12.0

12.0

5

4 .

10.0

1

8.0

2.0 
Table 4
C. Women only $\left(n=132^{\mathrm{a}}\right)$

Factor

Mental Stress e.g. Anxiety or Worry

Too Little sleep

: Mental and/or Physical Exhaustion

Eyestrain

Menstruation

Hunger

Alcohol and/or Drugs

Heat

Smoking

Too Much sleep

Hypertension

- Certain Foods

Exercise

Excitement

Unknown .

Flashing Light

constipation

Other
Number of Times Listed

114
109

107

99

72

71

41

39

37

34

24

24

$\checkmark 15$

14

14.

13

4

4
Percentage

of Subjects

86.4

82.6

81.1

$75.0^{\circ}$

54.5

53.8

31.1

29.5

28.0

25.8

18.2

18.2

11.4

10.6

10.6

9.8

3.0

3.0

Note

a 9

Sample size before deletion of outliers, disabling headaches, and incomplete questionnaires. 19 men and 21 women reported "no headache" and are therefore not included in this sample. 
possible while men chose 5.22 out of 17 possible.

C. Other Psychosomatic Symptoms

Table 5 gives a breakdown of the number of other psychosomatic symptoms listed, within the levels of severity of headache (no headache, mild, severe, and disabling) also showing men and women separately. Table 6 provides the results of $t$ tests comparing the means for the number of psychosonatic symptoms by level of headache severity. Of the six comparisons, two were significant : no headache with disabling headache $(\underline{t}(12.1)=-2.65, \underline{p}$ <.05), and mild headache with disabling headache ( $\mathrm{t}$ $(11.1)=-2.42, p<.05)$. Two other comparisons approached significance : no headache with severe headache (t (127) $=-1.87, \underline{p}=.06)$, and mild headache with disabling headache $(\underline{t}(11.1)=-1.96, \underline{p}=.07)$. The overall mean number of other psychosomatic symptoms was 1.14, with a standard deviation of 1.27 and a range of 0 to 5 . For women only, the nean nufuer of psychosomatic symptoms was 1.27, with a standard deviation of 7.29 and for men the mean was 0.88 , standard deviation 1.06 . The difference between these means efr men and women was significant with $t(220)=-1.96$, Within the levels of severity the only significant difference between men and women was in the severe headache category $(\underline{t} \cdot(78.1)=$ $-2.50, \mathrm{p}<.05)$. A Pearson Produat Moment correlation of $.22(p<.01)$ between headache severity and number of ..s. 
Table 5

Number of Other Psychosomatic Symptoms Listed, Shown separately for men and women within Levels of Severity of Headaches $(n=222: 69$ men, 153 women)

1. No Headache $(n=40 ; 19$ Mer, 21 Women)

$\begin{array}{lccc} & \frac{\text { Men }}{13} & \frac{\text { Women }}{21} & \frac{\text { Total }}{34} \\ \text { Mean per Subject } & 0.68 & 1.00 & 0.85 \\ \text { Number Listing Any } & 8 & 12 & \end{array}$

2. Mild Headache $(n=82 ; 23$ Men, 59 Women $)$

$\frac{\text { Men }}{20} \quad \frac{\text { Women }}{61} \quad \frac{\text { Total }}{81}$.

$\begin{array}{llll}\text { Mean per Subject } & 0.91 & 1.16 & 1.01\end{array}$

Number Iisting Any $\quad 11 \quad 34$

3. Severe Headache $(n=89 ; 24$ Men, 65 Women) Men Women Total

21 92 113

$\begin{array}{llll}\text { Mean per Subject } & 0.88 * * & 1.42 & 1.27\end{array}$

Number Listing Any $17 \quad 43^{*}$

4. Disabling Headache $(n=11 ; 3$ Men, 8 Women)

\begin{tabular}{llcr} 
& $\frac{\text { Men }}{6}$ & $\frac{\text { Women }}{20}$ & $\frac{\text { Total }}{26}$ \\
Mean per Subject & 6 & 2.5 & 2.36 \\
Number Listing Any & 2 & 8 & \\
\hline
\end{tabular}

** Means for men and women significantly different at $\mathrm{p}<.05$ 
Table 6

Comparison of Means for Number of Psychosomatic Symptoms By Levels of Severity of Headache

Level No Level of Severity Mean Number

N Significant Differences (Level to Level)

\begin{tabular}{lllll}
\hline 1 & .No Headache & 0.85 & 40 & $1-4 * \sqrt{ }$ \\
2 & Mild & 1.01 & 82 & $2-4 *$ \\
3 & Severe & 1.27 & 89 & Nil \\
4 & Disabling & 2.36 & 11 & $4-1 * 4-2 *$ \\
\hline
\end{tabular}

* Significant at $\mathrm{R}<.05$ 
psychosomatic symptoms was found, indicating that as headache severity increased the number of other psychosomatic symptoms reported also tended to increase. 2. Relationship of the Personality' Variables to Headache To investigate the relationship of the personality variables to headache severity and frequency, the following analyses were undertaken. First for all the variables, the means, standard deviations, minimum and maximum values are presented, followed by Pearson Product-Moment Correlations. Then Locus of Control, Assertiveness, Anxiety, Frequency and Severity of Headache, were dichotomized, using median splits (see Appendix $G$ ) and chi square tests performed. The results of t tésts on all variables examiningsex differences and differences between the dichotomized levels of frequency and severity are presented next. The three dichotomized personality variables were then examined for. relationships by combining them. First, after ANOVA analyses, multiple comparison procedures were used to test for significant differences between the neans of the eight combinations, when measured on headache frequency. and severity. Secondly, using the FUNCAT procedure (SAS, 1982), the observed frequency of those with headache, and those without headache, within each of the combinations, was compared to the expected frequency, using chi square tests. Multiple Regression analyses were then performed 
with the three personality variables and sex as the predictors, and frequency and severity as the criterion variables. Finally, mention will be made of two other analyses, including a MANCOVA with the personality variables as independent variables, the headache measures as dependent variables, and the sex of the subject as a covariate. Discriminant Function analyses were also perforined using the three personality variables as predictors of headiche frequency and severity. A. Means, Standard Deviations, Minimum and Maximum Valiues

Table 7 presents this information for all the personality variables and both measures of headache, based on the reduced sample of 195. These statistics are presented for men and women' separately as well as together. Anxiety was shown to have a higher than expected mean for the total sample at 65.95 , assuming a mean of 55 ( 5.5 in stens) is normally expected. (1) tests between men and women are shown in Table IIA). Overall, the mean frequency (FREQ) of headache of 3.57. and mean severity (SEV) of 2.21 indicated that the tendenoy, was for most of the subjects to have a headache every few months or so of nild severity. However, as shown in Table 3, approximately 67 percent of the sample reported either monthly or weekly héadaches (FREQ of 4 or 5 ), so the mean Prequency is rather misleading.' 
Tabie 7

A. Means, Standard Deviations, and Minimum and Maximum values of All Variables. $(\mathrm{n}=195)$

\begin{tabular}{lrrrr} 
Variable Name & Mean & $\begin{array}{c}\text { Standard } \\
\text { Deviation }\end{array}$ & Minimum & Maximum \\
\hline HIC & 35.04 & 5.56 & 21 & $49^{\circ}$ \\
IC & 11.28 & 4.00 & 1 & 20 \\
RAS & 48.23 & 17.38 & 8 & 96 \\
TYPE & 3.06 & 1.19 & 1 & 4 \\
Anxiety (ANX) & 65.95 & 16.72 & 22 & 105 \\
Extraversion (EXTRA) 56.43 & 18.25 & 10 & 101 \\
Tough Poise (TP) & 61.01 & 18.75 & 20 & 115 \\
Independence (INDEP) 56.58 & 17.52 & 15 & 112 \\
\hline
\end{tabular}

\section{PF Factors}

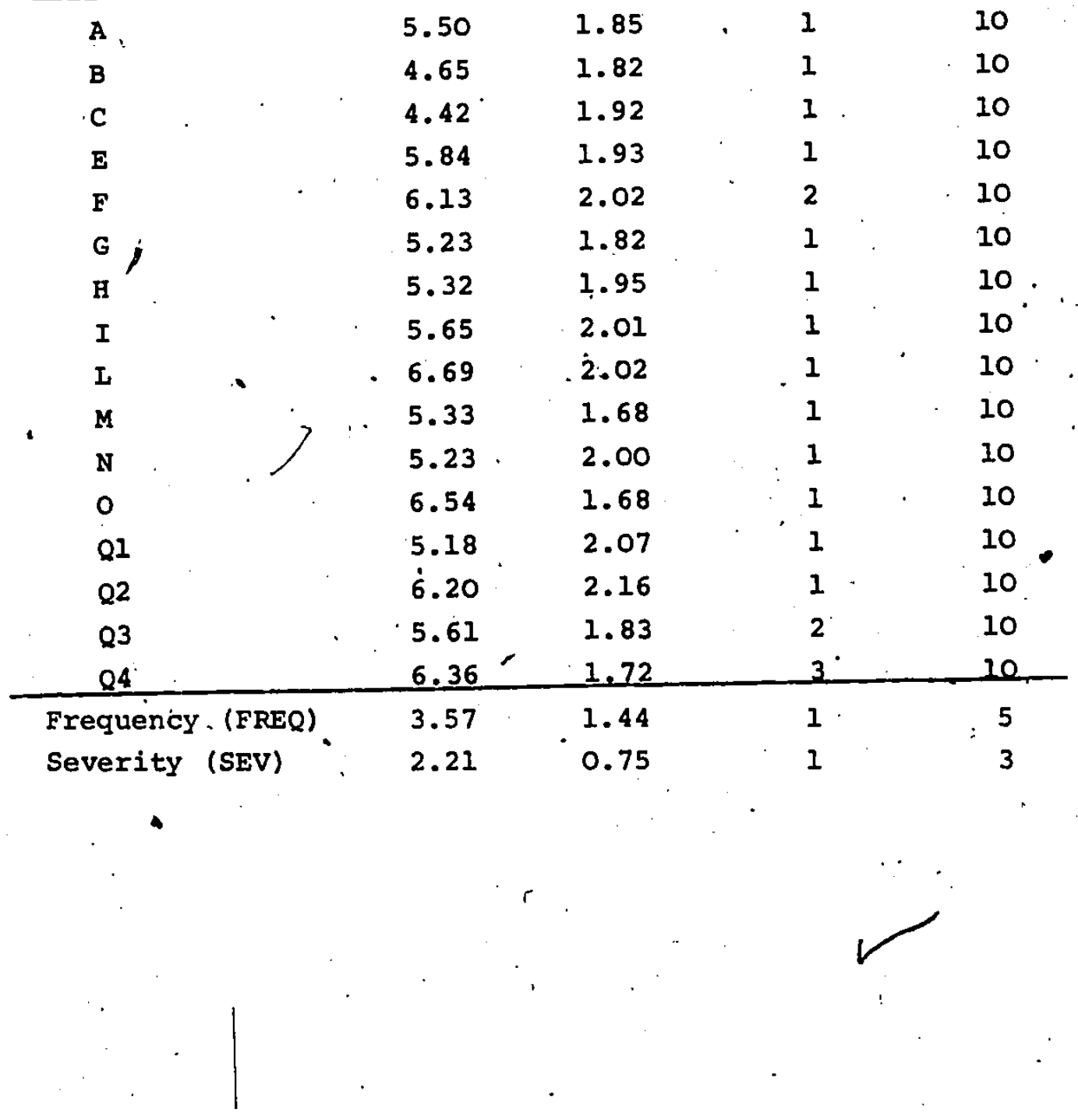


Table 7

B.. Means, Standard Deviations, Minimum and Maximum

Values of All Variables, Showing Men and Women

Separately $(n=195 ; 61$ men, 134 women)

\begin{tabular}{|c|c|c|c|c|c|c|c|c|}
\hline $\begin{array}{l}\text { Variable } \\
\text { Name }\end{array}$ & $\begin{array}{c}\text { Mean } \\
\text { Men }\end{array}$ & Women & $\begin{array}{c}\text { Standara } \\
\text { Mén }\end{array}$ & $\begin{array}{l}\text { Deviation } \\
\text { Women }\end{array}$ & $\begin{array}{l}\text { Mini } \\
\text { Men } \\
\end{array}$ & $\begin{array}{l}\text { Imum } \\
\text { Women }\end{array}$ & $\begin{array}{r}\text { Maxi } \\
2 \text { Men } \\
\end{array}$ & $\begin{array}{l}\text { imum } \\
\text { Women } \\
\end{array}$ \\
\hline $\mathrm{HLC}$ & 33.57 & 35.70 & 5.29 & 5.58 & 23 & 21 & 49 & 49 \\
\hline IC & 10.36 & 11.70 & 4.16 & 3.87 & 2 & 1 & 19 & 20 \\
\hline RAS & 52.92 & 46.09 & 16.40 & 17.45 & 16 & 8 & 86 & 96 \\
\hline TYPE & 2.84 & 3.16 & 1.31 & 1.22 & $I$ & 1 & 4 & 4 \\
\hline ANX & 64.54 & 66.66 & 15.92 & 17.23 & 27 & 22 & 96 & 105 \\
\hline EXTRA & 56.82 & 56.25 & 19.65 & 17.65 & 22 & 10 & 90 & 101 \\
\hline TP & 53.41 & 64.47 & 19.48 & 17.41 & 20 & 23 & 105 & 115 \\
\hline INDEP & 58.98 & 55.49 & 17.74 & 17.37 & 24 & 15 & 101 & 112 \\
\hline
\end{tabular}

\section{PF Factors}

\begin{tabular}{lrrrrrrrrr} 
A & 5.57 & 5.47 & 1.94 & 1.82 & 2 & 1 & 10 & 10 \\
B & 4.77 & 4.60 & 2.04 & 1.71 & 1 & 1 & 10 & 8 \\
C & 4.34 & 4.46 & 1.98 & 1.89 & 1 & 1 & 10 & 8 \\
E & 5.93 & 5.79 & 2.05 & 1.88 & 2 & 1 & 10 & 10 \\
F & 6.21 & 6.10 & 2.24 & 1.91 & 3 & 2 & 10 & 10 \\
G & 5.13 & 5.28 & 1.69 & 1.88 & 1 & 1 & 9 & 10 \\
H & 5.43 & 5.28 & 2.12 & 1.87 & 1 & 2 & 10 & 9 \\
I & 5.92 & 5.53 & 2.33 & 1.84 & 1 & 1 & 10 & 10 \\
I & 6.59 & 6.74 & 2.18 & 1.95 & 1 & 1 & 10 & 10 \\
M & 5.79 & 5.12 & 1.73 & 1.62 & 1 & 2 & 10 & 10 \\
N & 5.26 & 5.21 & 1.93 & 2.04 & 2 & 1 & 10 & 10 \\
O & 6.41 & 6.60 & 1.54 & 1.73 & 3 & 1 & 10 & 10 \\
Q1 & 5.84 & 4.89 & 2.02 & 2.03 & 3 & 1 & 10 & 10 \\
Q2 & 6.41 & 6.10 & 2.40 & 2.05 & 1 & 1 & 10 & 10 \\
Q3 & 5.54 & 5.63 & 1.58 & 1.94 & 2 & 2 & 9 & 10 \\
Q4 & 6.48 & 6.31 & 1.76 & 1.70 & 3 & 3 & 10 & 10 \\
\hline FREQ & 3.18 & 3.75 & 1.50 & 1.37 & 1 & 1 & 5 & 5 \\
SEV & 2.10 & 2.26 & 0.81 & 0.71 & 1 & 1 & 3 & 3 \\
\hline & & & & & & & & &
\end{tabular}




\section{B. Pearson Product-Moment Correlations}

Trbite 8 shows the significant correlations between thu thanularen of headache, the personality variables, sex, and type of headache, for men and women together, and also separately. The 16 primary or "first order" factors - of the 16PF were dropped from most of the subsequent unaryaes as they were considered well represented within tho four "second order" factors of Anxiety (ANX), lixtraversion (EXTRA); Tough Poise (TP), and Independence (INDEP). Also as thiese aecond order factors are more bromly braged they were considered to be generally more useful, in this study. As indicated in the tables, ANX had tho greatest number of significant correlations and mpart from type of headache (TYPE), was the only variable ralited to PREQ and SEV. The Health Locus of Control (inc) acoroo were wlso dropped from further analyses as ihes vere not considered useful in this study, being Pelinted only to the Iocus of Control (IC) scores, and to the nox of the subject. Further, EXTRA, TP, and INDEP wre dropped as none of them were significantly gorralnted 1 th the headache measures and seemed largely is Iupilonte tha contribution of RAS. These variables - are berefore consldered superfluous, in this study. A: hough TYPB had signiflcant correlations with FREQ.

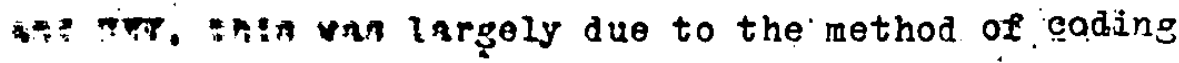
aftuges. to "no hoadachg" was coded "1" for TYPE, FREQ, 
- and SEV alike, this spuriously elevated the correlations between them. Univariate ANOVAS were performed, with FREQ, SEV, IC, RAS, and ANX used in turn as the dependent variables, and the four levels of TYPE as the independent variable. These analyses were not significant for $I C$, RAS, or ANX and multiple comparison tests revealed no significant differences between the means of the four lẹvels of TYPE (no headache, migraine, combined, and tension). Although the ANOVAs were significant for FREQ and SEV (due to the coding method), multiple comparisons showed no significant differences botween the means of : levels 2,3 , and 4 of TYPE. "These results Indicated that TYPE was not an important variable in this study, as the type of headache experienced by the subject had no relationship to his or her scores or ratings, on any of , the personality variables or headache measures. Some of the main findings shown in Table 8 are : (1). Sex of the subject was related to scores on the IC in that women tended to be more external than men. Women also tended to be less assertive (on the RAS), and have more frequent headaches.'.

(2) IC was related to RAS and ANX 'in that a more external score on the IC was related to a less assertive score on the RAS and to greater anxiety; as reported by the ANX score of the 16PF.

(3) As ANX increased FREQ and SEV increased also. 3

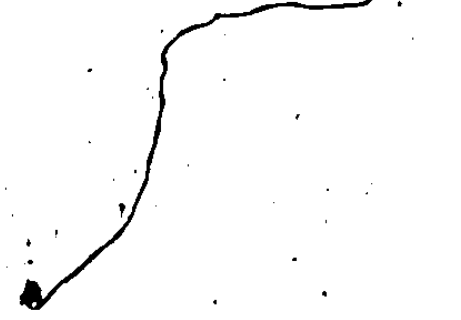


Table 8

A. Pearson Product-Moment Correlations for Variables with Significant correlations $(n=195)$

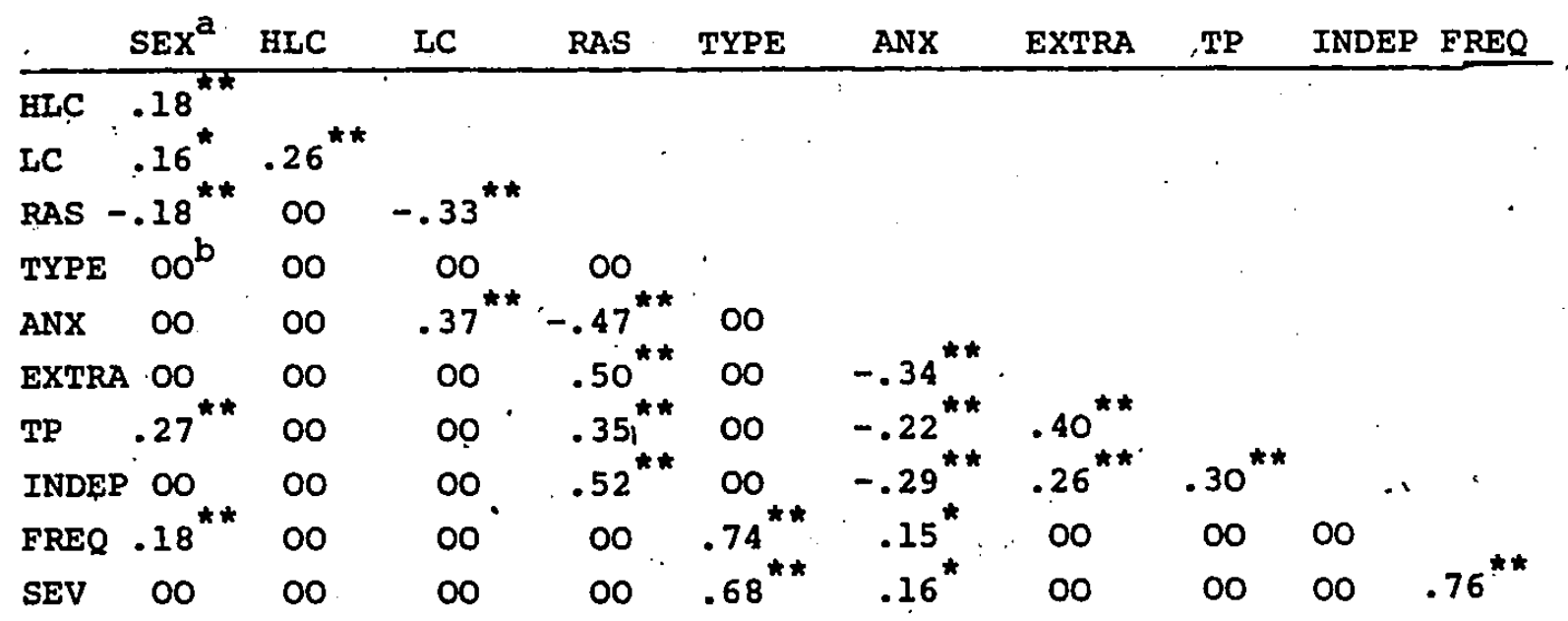

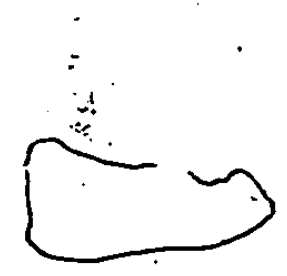

$\lambda$ 
Table 8

B. Pearson product-moment Correlations for Variables with Significant Correlations, Women only $(n=134)$

\begin{tabular}{|c|c|c|c|c|c|c|c|c|c|}
\hline & BLC & IC & RAS & TYPE & ANX & EXTRA & $T P$ & INDEP & FREQ \\
\hline LC & $.20^{\star}$ & & & 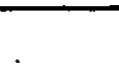 & & & & & \\
\hline RAS & $\infty$ & $.31^{\star}$ & & & & & & & \\
\hline TYPE & 00 & $\infty$ & & & & & & & \\
\hline $\mathrm{ANX}$ & $\infty$ & $.43^{\star}$ & -.44 & 00 & & & & & \\
\hline EXTRA & $\infty 0$ & $\infty$ & .49 & 00 & -.30 & & & & \\
\hline$T P$ & 00 & $\infty$ & .50 & 00 & $\therefore .23$ & $.56^{\pi}$ & & . & . \\
\hline INDEP & 00 & 00 & .54 & 00 & -.25 & $.21^{\star}$ & .40 & & \\
\hline FREQ & 00 & 00 & 00 & $.71^{8+}$ & 00 & $\infty 0$ & 00 & $\infty$ & \\
\hline SEV & 00 & $\infty$ & 00 & $.64^{k \hbar}$ & .19 & $\infty$ & 00 & $-.20^{\star}$ & .72 \\
\hline
\end{tabular}

C. Pearson Product-moment Correlations for Variables. with Significant Correlations, Men only $(n=61)$

\begin{tabular}{|c|c|c|c|c|c|c|c|c|c|}
\hline & HIC & LC & RÀS & TYPE & ANX & EXTRA & TP & INDEP & FREQ \\
\hline IC & $.31^{\prime \prime}$ & & & & & & & & \\
\hline RAS & $\infty$ & $-.32^{k x}$ & & & & & & & \\
\hline TYPE & 00 & 00 & $\infty$ & & & & & & \\
\hline ANX & $\infty 0$ & .00 & $-.54^{k \star}$ & 00 & & & & & \\
\hline EXTRA & $\infty$ & 00 & $.56^{\star *}$ & 00 & $-.44^{* \pi}$ & a & & & \\
\hline $\mathrm{TP}$ & $-.30^{\prime}$ & 00 & $.26^{\circ}$ & O० & $-.27^{*}$ & $\infty$ & & & \\
\hline INDEP & 00 & $-.27^{. x}$ & $.44^{n}$ & 00 & $-.39^{2 x}$ & $.36^{\pi / n}$ & $\infty$ & & \\
\hline FREQ & 00 & 00 & 00 & $.79^{x \pi}$ & 00 & $\infty$ & 00 & $\infty$ & \\
\hline SEV & 00 & 00 & oo & $.74^{* \hbar}$ & 00 & $\infty$ & 00 & $\infty$ & $.82^{2 k}$ \\
\hline
\end{tabular}

* Significant at $p<.05$

** Significant at $\mathrm{Q}<.01$

NOTES

a Men were coded as " 1 "; women as " 2 "

boo denotes a non-significant correlation 
However, this relationship was not very strong overall, with $\underline{r}=.15, p<.05$ for FREQ, and $\underline{r}=.16, p<.05$ for SEV. Finally, Table 9 provides the significant correlations when frequency of headache was held to the weekly category. Because of the smaller sample size, some correlations that were significant before with the full sample, became non-significant. However assertiveness (RAS) became the variable with the greatest number of significant correlations and the only one that correlated significantly with either of the headache measures. This suggests that, for those with the post frequent headaches, being nore assertive is related lo being less anxious, more internal, and having less'severe headaches.

\section{Chi-squzre Tests.}

Chi-square tests were perforinel on each of the pairings of the dichotomized variables TC, RAS, AiVx, FRTR and.SEV, to investigate whether the observed cell erequencies were significantly different from the expected frequencies. These tests provided an overall chi-square statistic for each of the ten pairings, which indicated whether or not a significant difference existed sonewhere between the observed and expected frequencies found in the four cells. Further chi-gquare tests were then performed to determine which of the four cell frequencies differed significantly from the 
Table 9

Pearson Product-Moment Correlations for Variables with

Significant correlations, for weekiy Headaches only $(n=59)$

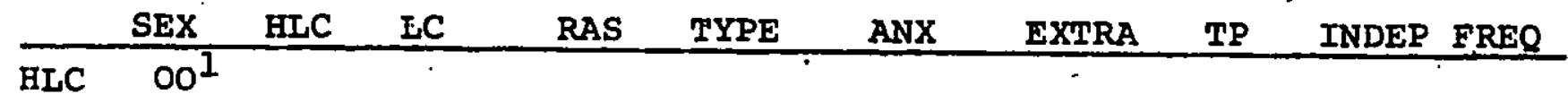

IC $00 \cdot 00$

RAS 00 OO $-.31^{\star \star}$

TYPE OO $00 \quad 00$

ANX 00 OO $.42^{\star \star}-.45^{\star \star}, 00$

EXTRA 00 OO $00 \quad .42^{\star *}$, $00 \quad-.30^{*}$

TP $\angle 26^{*} 00 \quad 00 \quad .48^{*}: .00 \quad-.28^{*} \quad .52^{* *}$

INDEP $0000 \quad 00 \quad .40^{* *} 00 \quad 00 \quad 00.00$

$\begin{array}{llllllllll}\text { FREQ } & -2 & - & - & - & - & - & - & - & - \\ \text { SEV } & 00 & 00 & 00 & -.28^{\star} & 00 & 00 & 00 & 60 & 00\end{array}$

* a Significant at $\mathrm{p}<.05^{\circ}$

$\star \star$ Significant at $\mathrm{p}<.01$

NOTES

1. 00 denotes a non-significant correlation

2. Correlations between FREQ and other variables are not provided as FREQ was held to one level 
expected frequency. Median splits were made for each of these variables (as shown in Appendix $G$ ), but because the scales involved whole nunbers, the group sizes above and below the median were not exactly equal. The results, shown in Table 10, revealed significant differences, frorn the expected cell frequencies, for four of the pairings. (i) IC by RAS. Significantly more subjects were found in the two ceils representing internal/more assertive and external/less assertive.

(2) IC by ANX. Significantly more subjects were found in the two cells representing internal/lower arixiety and external/higher anxiety.

(3). RAS by ANX. Significantly more subjects were found .

in the two cells representing less assertive/higher anxiety and more assertive/lower anxiety.

(4) FREQ by SEV. Significantly more subjects were found

\in the two cells representing more frequent/more severe headaches and, less frequent/less feyere headaches. These results confirmed the findings of Table 8, again suggesting that internal subjects tended to be more assertive and ibuer in anxiety, and that external subjects tended to be Iess assertive and higher in anxiety. 1. 
Table 10

Chi-squares for Each of the Pairings of the Dichomized Variables IC, RAS, ANX, FREQ, and SBV ( $\mathrm{n}=195)$

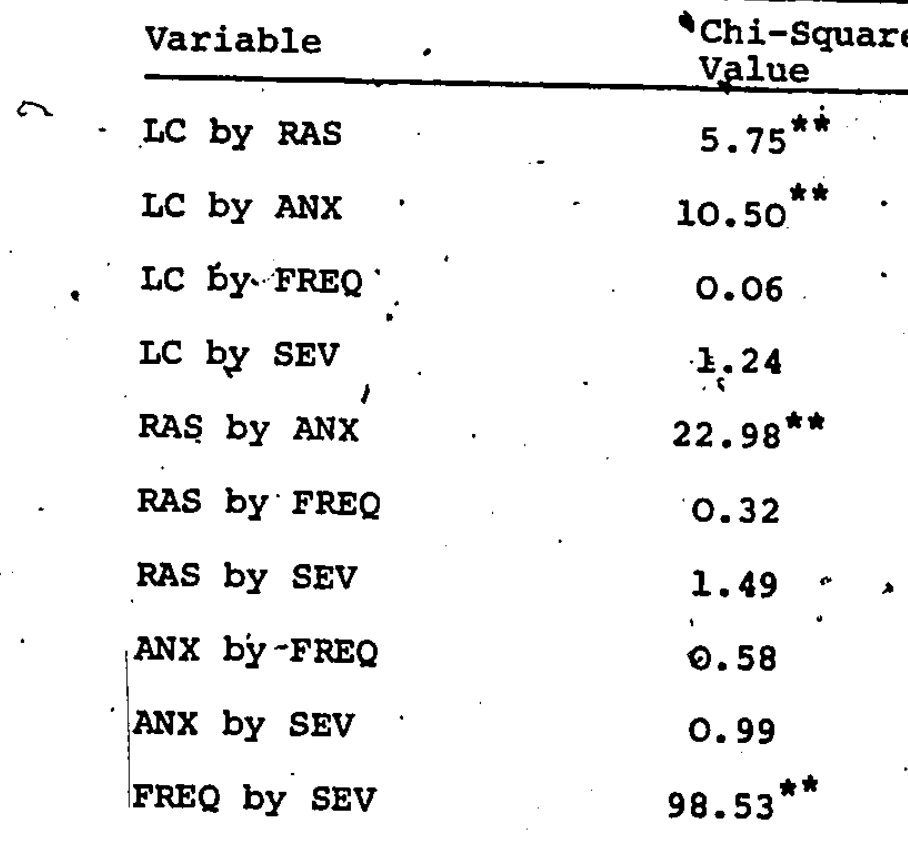

is ** significant at $\mathrm{p}<.01$. 

Table 11

T. Tests Showing Variables with Significant Differences;

A. By Sex $(n=61$ for men; $n=134$ for women)

\begin{tabular}{lccl} 
Variable Name & T Value & DF & Direction of Difference \\
\hline HLC & $\star *-2.51$ & 193.0 & Women higher \\
LC & $\star-2.19$ & 193.0 & Women higher \\
RAS & $* * 2.58$ & 193.0 & Men higher \\
TP & $\star \star-3.96$ & 193.0 & Women higher \\
FREQ & $\star \star-2.37$ & 193.0 & Women higher \\
M & $* \star 2.61$ & 193.0 & Men higher \\
Q1 & $\star * 3.03$ & 193.0 & Men higher \\
\hline
\end{tabular}

B. By Frequency of Headache, Dichotomized into - Group 1:

No Headache, Less than Yearly, and Yearly Vs. Group 2:

Monthly and Week Iy $(n=65$ for Group 1 and 140 for Group 2)

Variable Name $\quad T$ Value $\quad$ DF $\quad$ Direction of Difference

SEX

$\star-1.98 \quad 193.0$. Group 2 higher (Women higher

frequency)

$\begin{array}{llrrr}\text { SEV } & \star \star-9.72 & 92.7 & \text { Group } 2 \text { higher } \\ 0 & \star & \star-2.04 & 105.5 & \text { Group } 2 \text { higher } \\ \text { Q4 } & & \star-2.24 & 193.0 & \text { Group } 2 \text { higher }\end{array}$

C. By Severity of Headache Dichotomized into - Group 1 , No Headache VS Group 2 , Mild and Severe Headaches $(n=38$ for Group 1 and 157 for Group 2)

\begin{tabular}{|c|c|c|c|}
\hline Variable Name & T Value & $\mathrm{DF}$ & Direction of Difference \\
\hline SEX & $\star-2.00$ & 193.0 & Group 2 Higher \\
\hline 0 & $\star-2.03$ & 193.0 & Group 2 Higher \\
\hline 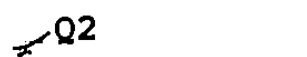 & $\star 2.23$ & 193.0 & Group 1 Higher \\
\hline
\end{tabular}

* Significant at $p<.05$

* significant at $\mathrm{p}<.01$ 
Table 72

Table of Means for FREQ and SEV by the Dichotomized Variables IC, RAS and ANX

\begin{tabular}{lrrrrrr} 
Variable & N Level & & $\begin{array}{c}\text { FREQ } \\
\text { Mean }\end{array}$ & Level & $\begin{array}{l}\text { SEV } \\
\text { Mean }\end{array}$ \\
\hline \multirow{2}{*}{ LC } & 103 & 1 & 1 & 3.57 & 1 & 2.19 \\
& 92 & 2 & & 3.57 & 2 & 2.23 \\
RAS & 101 & 1 & & 3.55 & 1 & 2.26 \\
& 94 & 2 & 3.59 & 2 & 2.16 \\
ANX & 96 & 1 & & 3.46 & 1 & 2.16 \\
A & 99 & 2 & 3.68 & 2 & 2.26
\end{tabular}

NOTE

No significant differences/between the two means for each of . the variables, were found, using te tests.

7

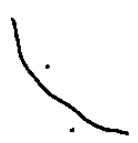

1

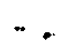

$+$

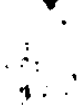


E. Multiple Comparison Tests

First, a MANCOVA (a multivariate analysis of variance with a covariate), was perforned using the General Iinear Models procedure (SAS, 1982), with frequency and sorerity of headache as dependent variables, SEX as a covariate, and IC, RAS, and ANX as independent variables. Multiple comparison tests between the means of the eight combinations of the three dichotomized personality variables (LC, RAS, and ANX),

7 were then performed. The results are shown in Table $13 \mathrm{~A}$. No significant differences were found for headache frequency. For headiche severity only the mean of the internal, less assertive and more anxious combination . (Number 2) was found to be significantly different from more than one of the other combination means. This combination, however, was not significantly different from the combination of external, more assertive and more anxious (Number 1). Overall, these results do not reveal any clear differences between any of the combinations, when measured on headache erequency or severity. - After ANOVA analyses, with each of the variables used, in turn, as the dependent measure (for exploratory. purposes), further multiple comparisons were made between the means of the combinations. Table 13B shows the results when ANX was used as the dependent measure with LC, RAS, and FREQ as independent variables. The highest 
Table 13

Means for FREQ, SEV, and ANX, for the Eight Combinations of the Dichotomized Variables $(n=195)$

A. Means for FREQ and SEV

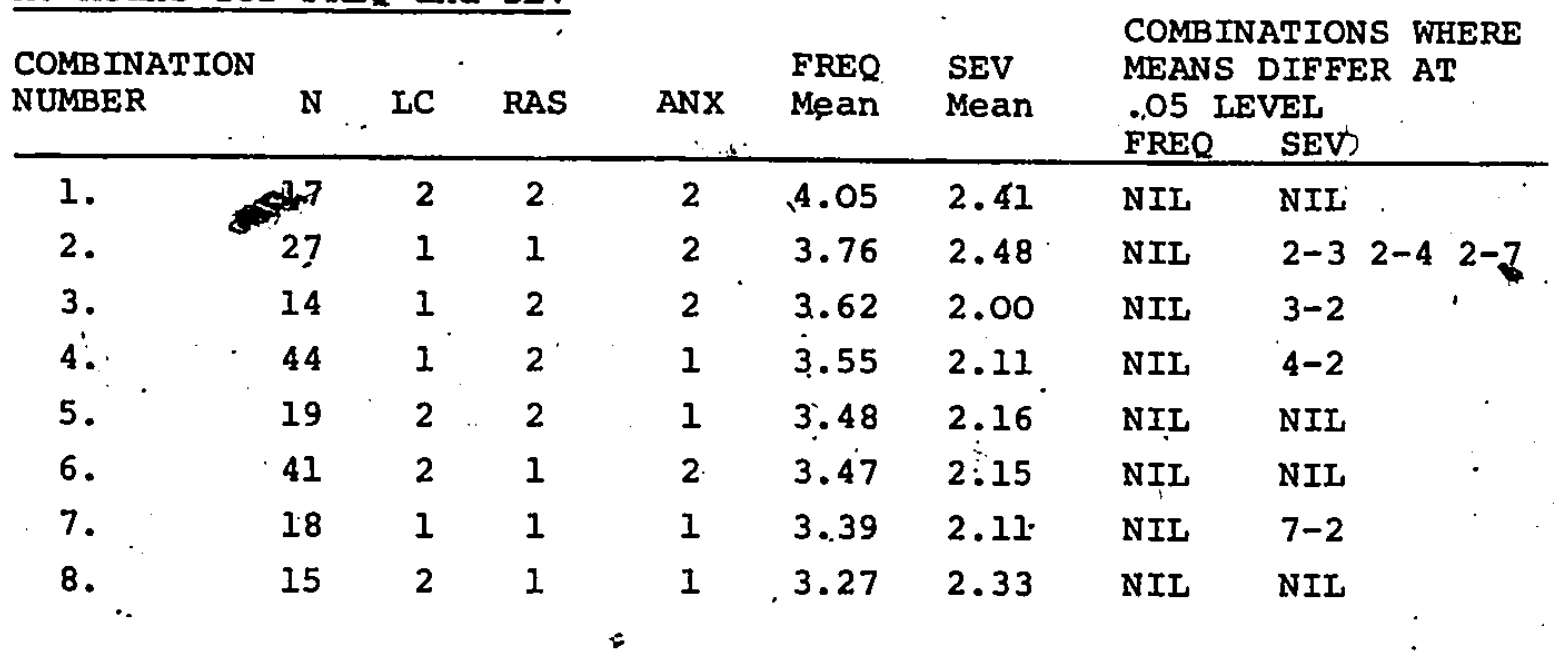

B: Means for ANX

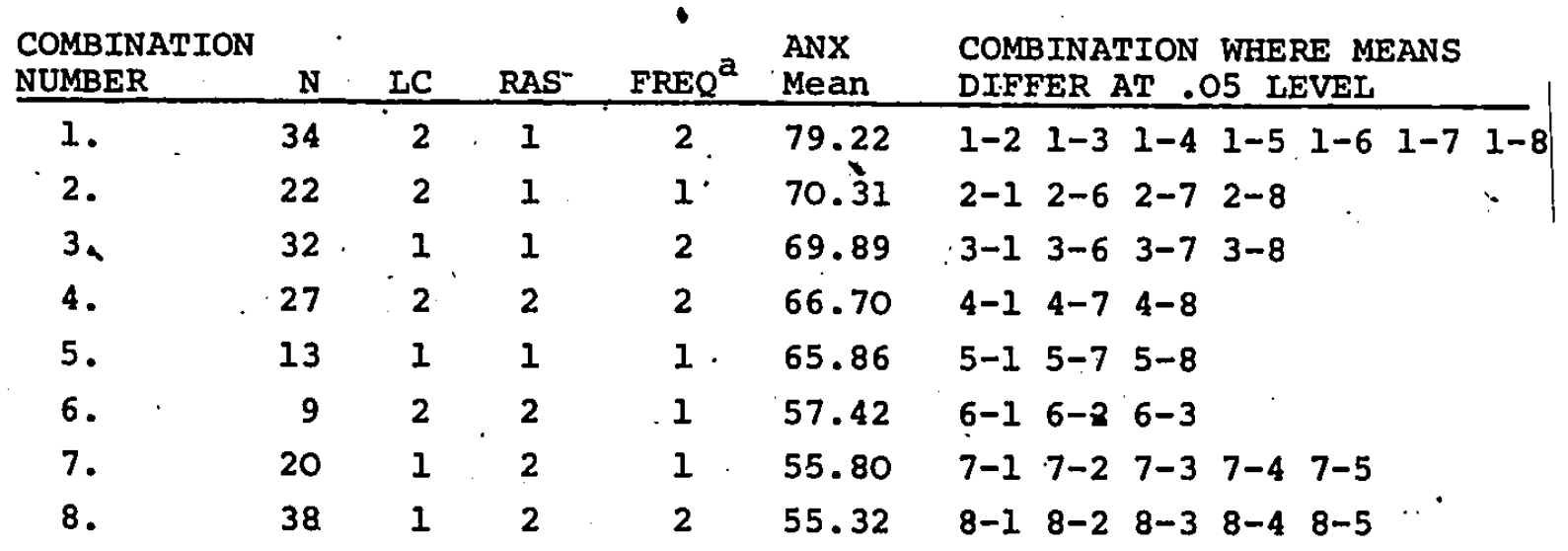

NOTE

a For $F R E Q=1, n=64 ;$ For $F R E Q=2, n=131$ 
mean for ANX (Number 1) involved those who were external, lower in assertiveness and who had more frequent headaches (see Appendix, $G$ for details of the dichotomy, used for FREQ). However more frequent headaches. also occurred when ANX was at its lowest. In this case (Combination Number 8), the subjects tended to be internal and more assertive in contrast to external and less assertive as found in Combination Number 1 . Other analyses, using.IC frd RAS as the dependent measures, in turn, and substituting $S E V$ for $F R E Q$ as an independent variable, did not reveal any clearly interpretable results. F. Rasponse Frequences for the Eight Combinations of the Dichotomized Variables, IC, RAS, and ANX

The FUNCAT procedure (SAS, 1982) was used to measure the frequency counts for each of the eight combinations As Table 14 shows, the largest number of subjects were found in te two groups which included internal, more assertive, and Iess anxious subjects (Combinafion Number 1) or external, less assertive, and more anxious subjects (Combination Number 2). The diatribution of the frequency counts for the eight combinations was

approximately normal, with the largest number of subjects falling into the categories that would be expected to be more frequent, based on findings by earlier researchers. For example those who are less anxious may be expected 
- Parie it

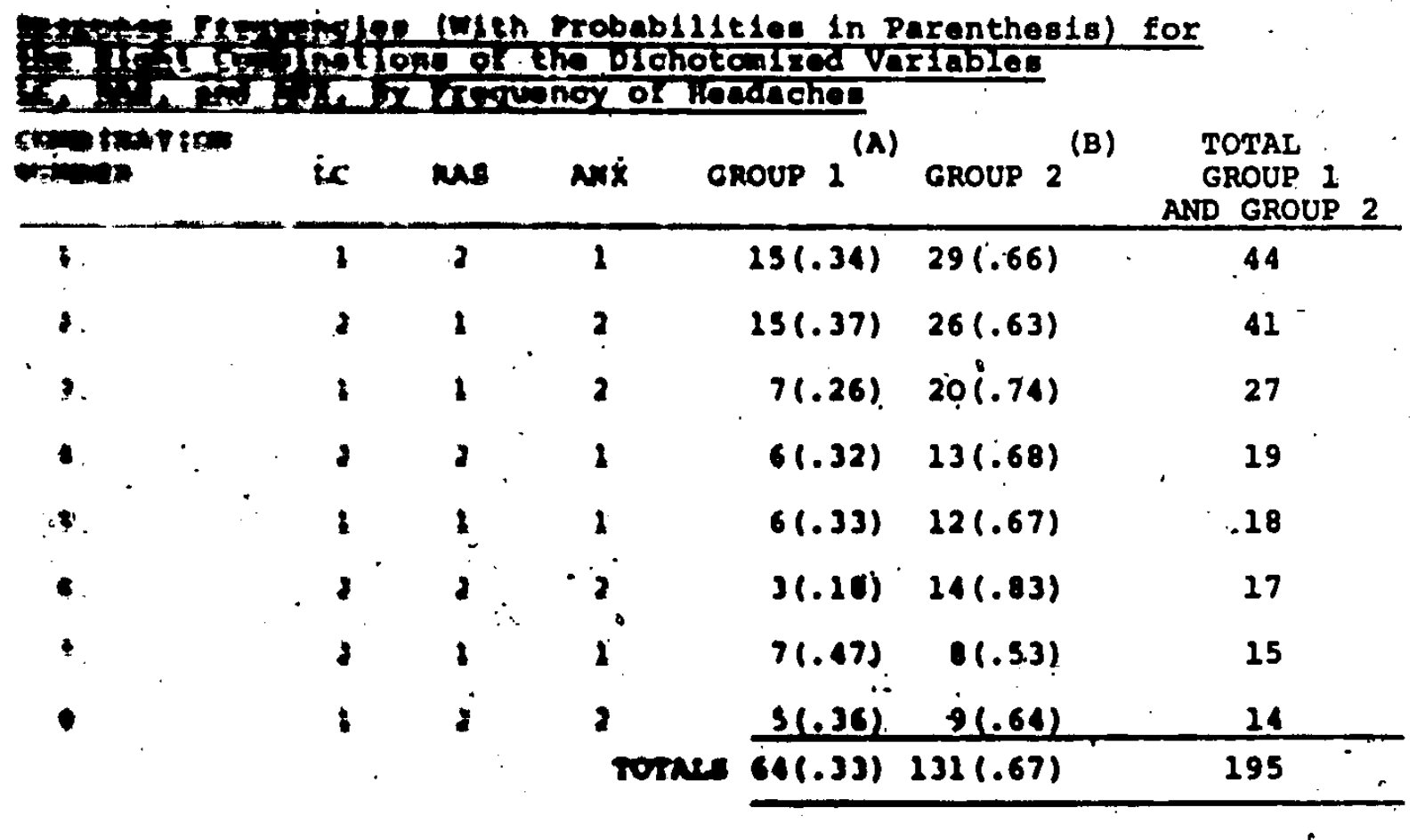

$\ldots: \cdots$

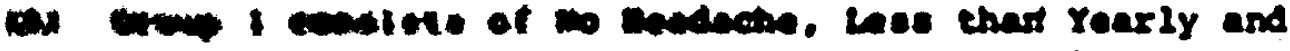

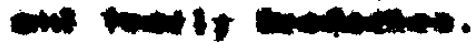

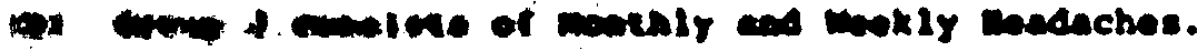




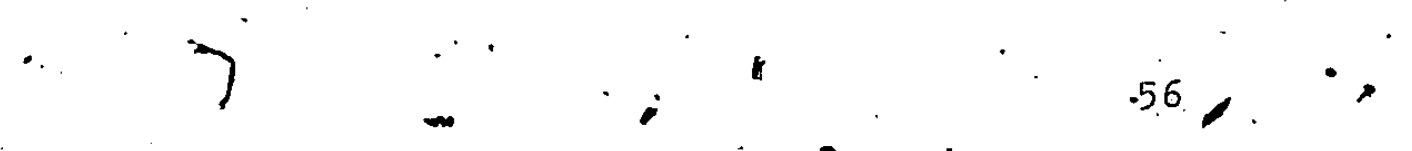

to be more assertive and internal, whereas those who are more anxious would be less likely to be internal ang-more $<$ assertive (Combination Number 8). Accounting for the different frequencies in this way suggests that the number of subjects in each combination. was a function of something other than headache frequency: Therefore the. most appropriate way to investigate whether any of these combinations was significantly related to headache frequency, was to compare the frequencies of less vs. more frequent headache, within each combination. Chi square tests were used to test whether any of the observed frequencies differed significantly from the expected. (For ease of comparisoy, proportions are also shown in Table 14). The expected proportiv was .33 (64/195) for Group 1, consisting of no headache, less - than yearly, and yearly heatroches; and .67 (131/195) for Group 2, consisting of monthly and weekly headaches. No significant differences were found, for any of the combinations, in this regard.-

Táble 15 shows the frequency of responses for the eight combinations measured by severity, dichotomized in two different ways: Table 15A has Group I, consisting of no headache and mild headache vs." Group 2, consisting of severe headaches. Table I5B has Group I consiating of no headaches vs. Group 2, consisting of mild and severe. headaches. Table 16 shows the same two dichotomies of 
Table 15

Response Frequencies (With Probabilities in parenthèsis) for the Eight Combinations of the Dichotomized variables LC, RAS and ANX, By Severity of Headaches

A. Group 1 consists of No Headaches and Mild Headaches : Group 2 Consists of Severe Headaches

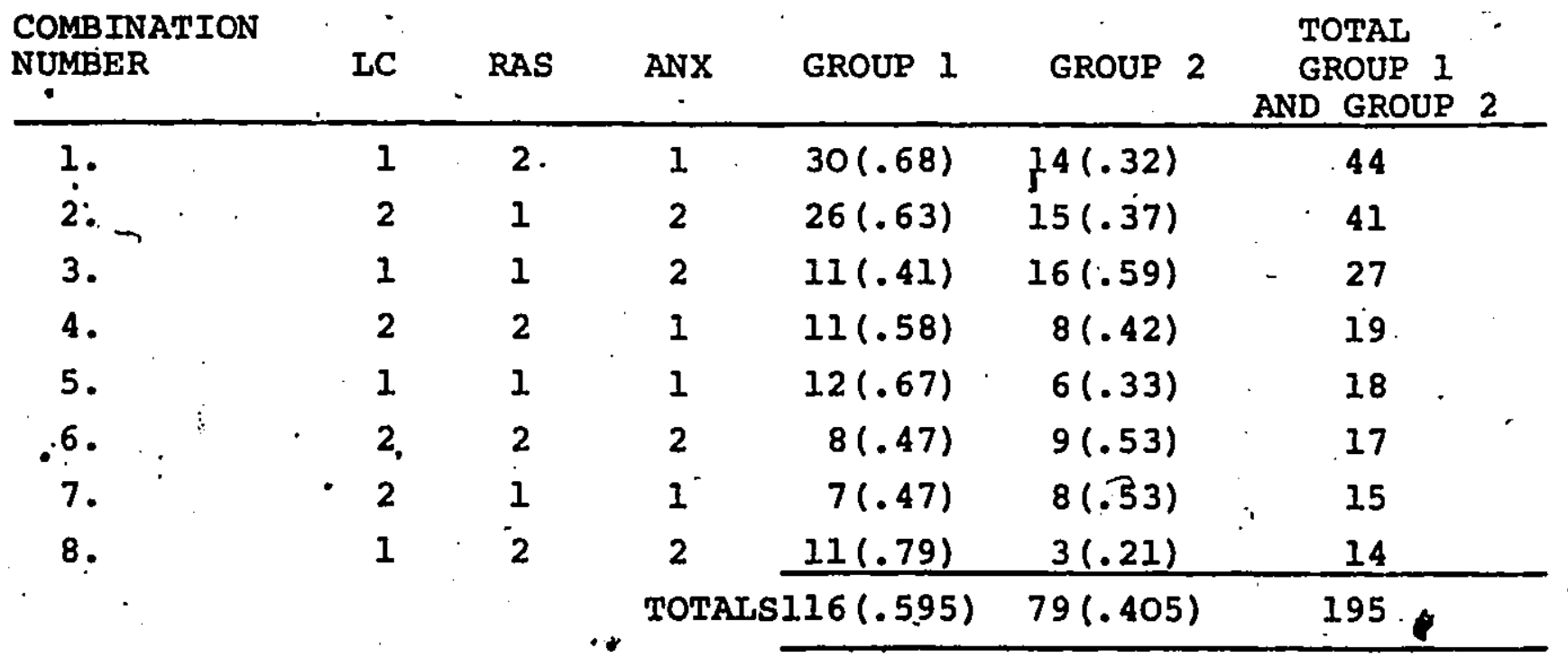

B. Group 1 consists of No Headaches : Group 2 Consists of Mild and Severe Headaches

COMBINATION NUMBER

$1:$
2.
3.
4.
5.
6.
7.
8.

IC RAS ANX GROUP 1

GROUP. 2. TOTAL AND GROUP :

\begin{tabular}{llllll}
1 & 2 & 1 & $9(.20)$ & $35(.80)$ & 44 \\
2 & 1 & 2 & $9(.22)$ & $32(.18)$ & 41 \\
1 & 1 & 2 & $3(.11)$ & $24(.89)$ & 27 \\
2 & 2 & 1 & $5(.26)$ & $14(.74)$ & 19 \\
1 & 1 & 1 & $4(.22)$ & $14(.78)$ & 18 \\
2 & 2 & 2 & $2(.12)$ & $15(.88)$ & 17 \\
2 & 1 & 1 & $3(.20)$ & $12(.80)$ & 15 \\
1 & 2 & 2 & $3(.21)$ & $11(.79)$ & 14 \\
\hline
\end{tabular}


Table 16

Response Freguencies

the Elght Combinations of and ANX Showing Men and the Dlchotomized Variables, IC, RAS

A. By. Severity of Headaches

Mroup I Consists of No Headaches: Group 2 Consists of

COMBINATION

NUMBER

1.1

2.

3.

4.

9

5.

6.

$-7$. LC . RAS

12

21

12

22

11 .

22 ,

11

21
GROUP I AN

ANX

$15(.31)$

$4(.14)$

$23(.30) 6(.19)$

$2 \cdot 2(.22)$

$1(.20)$

$11(.513)$

$4(.36)$

2

$1(.17)$

$2(.10)$

$21(.20) \quad 1(.08)$

$13(.75) \cdot 1(.07)$

$12(.33) \quad 2(.17)$

$1 \quad 1$

$17(.28) 21(.16)$
GROUP 2 MEN

$11(.69) 24(.86)$

$7(.70)$

$7(.78)$

$25(.81)$

$7(.87)$

$4(.80)$

$7(.64)$

$5(.83) 19(.90)$

$4(.80) 11(.92)$

$1(.25) 13(.93)$

$2(.67) \quad 10(.83$

$44(.72) 113(.84)$
TOTAL MEN WOMEN

1628

$10 \quad 31$

95

811

621

$5 \quad 12$

414

$3 \quad 12$

B. By Frequency of Headaches Group I Consists. of No Headache, Less than Yearly and Yearly COMBINATION NUMBER GROUP I

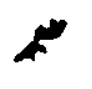

1.

2.

LC

3.

4.

5.

1

1 . 2
ANX MEN 1

$2 \cdot 1 \cdot 7(.44) \quad 8(.29) \quad 9(.5$

GROUP 2

$61 \quad 134$

$61 \quad 134$


headache severity separately for men and women. Chisquare tests weré performed and no significant differences, for any of the combinations on Tables 15 or 16, were found between the observed and of pected frequencies of lesser or greater severity. However these non-significant findings may be partly due to the small number of counts, especially for male subjects, found in some cells. It seems clear though that any effect for the three personality wariables, even with a larger sample, would be fairly weak. G. Multiple Regression Models

To examine the relationships between headache frequency and severity, as dependent variables on one side, and in linear combination of the three personality variables and sexys predictors on the other, multiple regression analyses were performed. Table 17 presents the reaults of the analysis. With headache frequency as the dependent variable. The model was significant ( $\underline{R}^{2}$ of .06 , $\mathrm{p}(.05)$ and SEX had a significant amount of unique "variance $\left(\underline{\mathrm{gr}}^{2}=.033, \underline{p}<.01\right)$ as did $\mathrm{ANX}\left(\underline{\mathrm{sr}} \mathrm{r}^{2}=.022, \underline{\mathrm{p}}<.05\right)$. Without IC and RAS partialled out the variance for ANX was slightly lower $\left(\underline{r}^{2}=.019, \quad \underline{p}=.07\right)$. This suggests that IC and RAS were supressing ANX somewhat, although the amount of change is small (.003). The multiple regression with SEV as the dependent variable, was not significant. 
Table 17

Summary Table for the Multiple Regression Analysis Showing the Relationship of SEX, ANX, $\mathrm{IC}$, and FAS to Headache Frequency

Source

Model

DE SS SS

Error

424.20
$\checkmark$

Total

$194 \quad 3.99 .82$

Semi-Partial Correlations squared $\left(\mathrm{sr}^{2}\right)$

$\operatorname{SEX}=.033 * \pi$

$\operatorname{ANX}=.021 *$

IC $=.000$

RAS $=.007$

* Significant at $p<.05$

** Significant at $p<.01$

$\begin{array}{ccc}M S & F & R^{2} \\ 6.05 & 3.06 & 0.061 \\ 1.98 & (p=.018)\end{array}$




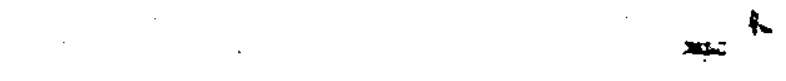

To investigate whether a sample consisting of the seemingly nost pathological headache yroup would show stronger relationships, those cases with weekly frequency of headache were selected. The result of this analysis is shown in Trable is. The $\underline{R}^{2}$ of . 109 was not significant. and although RAS approached significance $\left(\underline{\mathrm{sr}}^{2}=.057, \underline{\mathrm{p}}\right.$ $=$ (.06), none of the variables had a signipicant unique variance with headache severity.

H. Other Analyses

The following analyses were also performed:

(1) MANCOVA and ANOVA. With FREQ and SEV as dependent variables, LC, RAS, and ANX as independent variables (coded for levels as shown in Appendix G), and SEX as a covariate, the MANCOVA was not significant. No overall significant effect for LC X RAS X ANX was found, although this interaction approached significance when tested usịng Wilks' Criterion $(\underline{F}(2,185)=2.24, \underline{p}=.10)$. Two univariate ANOVAs were performed and a significant effect for SEX was found, with $\mathrm{FREQ}$ as the depentent variable ( $\underline{F}$ $(1,186)=6.42, p<.01)$. The IC X RAS X ANX interaction was significant with SEV as the dependent variable, ( $(1,186)=3.95, \mathrm{p}^{<.05)}$ and this was investigated further as reported earlier under "Multiple Comparison. Tests". (2) Discriminant Functions. An attempt was made to discriminate between the five levels of headache 


\section{6?}

Table 18

Summary Table for the Multiple Regression Analysis Showing the Relationship of LC, RAs, sNX, and SEX to Headache Severity, for Weekly Headaches only $(n=59)$

\begin{tabular}{lrrrrr}
\hline Source & DF & \multicolumn{1}{c}{ SS } & MS & F & $\mathrm{R}^{2}$ \\
Model & 4 & 7.532 & 0.383 & 1.65 & $.109 \%$ \\
Error & 54 & 12.502 & 0.232 & $(\mathrm{p}=.17)$ \\
Total & 58 & 14.034 & & &
\end{tabular}

Bemi-Partial Correlations squared $\left(s r^{2}\right)$

IC $=.019$

RAS $=.057$

$\mathrm{ANX}=.009$

SEX $=.011$ 
frequency using IC, RAS, and ANX as predictors. Only 38 percent accuracy was obtained and the discriminant function analysis failed to correctly classify any of the cases in the no headache, less than yearly, and yearly headaches categories. Discrimination between the three classes of. severity, using the same three variables, was 47 percent accurate overall, with most misclassifications being made on the "no headache" level. The results of these analyses suggest that knowing a subject's locus of control, level of assertiveness and anxiety, does not lead to a reliable prediction of headache frequency or severity.

Summary of Results

I. Results Describing the Sample

Approximately 82 percent of the total sample

- reported experiencing headache, with 37.1 percent reporting monthly headaches and 31.7 percent reporting weekly headaches: A higher proportion of men (26.9\%) reported no headaches, compared to women (13.9\%) and a highér proportion of women $(37.1 \%)$ reported weekly headaches, compared to men (19, $4 \%)$. Approximately 53 percent of all subjects were clasisified as having tension type headaches, but as the method used to classify headaches is only 68.2 percent accurate, no weight should be placed on the findings concerning headache type. The factors liated most frequently by the total 
sample as precipitating headache were, "mental stress". and "mental and/or physical exhaustion". Approximatel $\dot{y}$ 80 percent of the men and women listed these two factors, closely followed by the factor "too little sleep". The

1 most popular choice for women was "mental stress" (86.4\%) and for men "mental and/or physical exhaustion" (76.0\%): On average, women reported significantly more "other psychosomatic symptoms" than men, with a mean 'of 1.27 symptoms conpared to 0.88 symptoms for men $(\underline{t}(220)=$ $-1.96, p<.05)$. By level of severity, the no headache. and mild headache levels both differed significantly from the disabling headache level ( $\mathrm{ps}<.05)$. The comparisons of the no headache level to the severe headache level and mild headache to disabling headache, both approached $\rightarrow$ significance with ps of .06 and .07 , respectively. The correlation between headache severity and the number of other psychosomatic symptoms was .22 ( $p<.01)$; which indicated that as headache severity increased the number of symptoms reported also tendet to increase. 2. Results Concerning the Relationship of the Personality Variables to Headache (1) Relationship of LC to Headache.

No significant correlations were. found between IC and FREQ or SEV. When IC was dichotomized and neasured on headache frequency and severity, t-tests showed that the neans of the internal group were not significantly 
different. from the means of the external group. Chi. square tests for differences between the observed and expected cell frequencies of $I C$ and FREQ, and $I C$ and $S E V$, were also not significant.

(2) Relationship of RAS to Headache

Although no significant correlations were found between RAS and FREQ or SEV when the whole sample was used, 'ंAS did have a significant correlation with SEV ( $\underline{r}$ $\ldots=-.28, \mathrm{p}<.05)$ when the sample consisted only of subjects with weekly headaches. When RAS was dichotomized and measured on headache frequency and severity no significant differences were found between the means of the less assertive group and the more assertive group, using t tests. Chi square tests between the observed and expected cell frequencies of, RAS and FREQ, and RAS and SEV were not significant.

(3) Relationship of ANX to Headache

The Pearson product-moment correlations between ANX afd FREQ of. 15 ( $p<.05)$, and ANX and SEV of .16 ( $p<.05)$; Indicatid that as frequency and severity of headaches increased, reported anxiety tended to increase also. : When correlations were obtained for men and women separately, only the correlation between ANX and SEV for ( women was significant $(\underline{r}=.19, \underline{p}<.05)$, so this relationship did not seem very robust. Using t tests, no significant differences between the means of the less. 
anxious group and the more anxious group, of the

dichotomized variable ANX, were found, when measured on . headache erequency and severity.

\section{(4) Relationships Between IC, RAS, and ANX}

As indicated by significant Pearson Product-Moment correlations, an external score on the IC was related to a less assertive score on the RAS and to higher anxiety. as indicated by the ANX score of the 26PF. It was also noted that the largest number of subjects (44) fell into the internal, more assertive, and less anxious group, closely followed by the external, less assertive, and more anxious group (4I șubjectis). The distribution of the frequency counts for the elght combinations wasiseen to be approximately normal, with the greatest number of subjects found in the combinations which were expected to be more frequent, based on findings by other researchers. (5) Relationship of the Combinations of IC, RAS, and ANX to Headache

None of the means of the eight combinations of the three personality variables, were found to be. significantly different, whe FREQ was used as the dependent measure. When SEV was the dependent measure only one combination, internal, less assertive, and more anxious, had a mean that was significantly different from more than one of the other combination means. This combination had the highest mean for SEV, but was not. 
significantly different from the next highest mean, which . was the external, nore assertive, and more anxious combination. Although the two highest combination means for: Siv both included subjects reporting higher anxiety, the: conbination with the lowest mean for SEV also included subjects with higher anxiefy. No clear refationship between the eight combinations and headache severity or frequency, was therefore dehenstrated. $\therefore$ Chi- , square tests were used to test for significant.

differences between the observed and expected frequencies of groups, within each of the combinations. The groups were either dichotomizations of the severity measures or . of the frequency measures. No-significant differences were found for any of the combinations, in this regard. A multiple regression analysis revealed a significant relationship between the three,personality variables (IC, RAS, and ANX) and frequency of headache, only when the sex of the subject was included as a predictor. With FREQ as the dependent variable, SEX and ANX contributed a significant amount of unique variance to. the total variance of FREQ. Also, it was found that - IC and RAS Bupressed ANX somewhat. With SEV as the dependent variable, the three personality variables, and SEX dis predictors, the multiple regression was not significant." 
CHAPTER $1 \mathrm{~V}$

Discussion

The main purpose of the study was to examine the

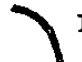
relationship between three personality variables, locus fof control, assertiveness and anxiety, and headache Irequency and severity. Only anxiety is shown to be. significantly related to headache, although the relationship is rather weak. However, there are several significant relationships between the personafity variables themselves. It appears that these personality : variables are not very useful in the prediction of headache frequency or severity, either combined or individually. The first part of this.chapter will discuss this further and offer an explanation for the findings. The second part wili compare the findings concerning headache incidence, type, and precipitating factors, with those in the existing literatare and discuss some-related issues,

1. Relationships of the Personality. Variables to

\section{Headache :}

The search for a "headache personality" has continued for many years, with gonflycting findings and conciusions. -In terms of the twoimein types of headache, Bakal (1975), in his litergtre review, concluded there. was no definitive mitraifous personality", esd Friedman (1979) found that no speoific personality was in evidence 


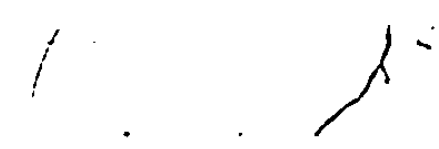

for tension headaches. Yet the idea persists that people who suffer fromirequent and gevere healaches are somehow "different" from others, in terns of personality characteristicis.

Neuroticism and depression have been two personality characteristics frequently connected to headache activity. As discussed earlier, studies have provided evidence to support the relationships although they are

$\downarrow$ far from conclusive. Also the research mainly involved "headache patients," who may well have had more pervasive personality disorders than, for example, university. s.tudents. These findings then, may not be particularly useful or relevant in headache research dealing with non-patient populations.

Another important area in the search for a relatiofship between personality variables and headache, is that of anxiety. It is a common belief that anxiety is related to headache, and headache is generally assumed to be ope of the physiological manifestations of anxiety. It would seem then, that the relationship between anxiety and headache should be a strong one. In the present study, anxiety is shown to have some relationship to? headiache, but this relationship is rather weak. "Several' other researchers (e.g. Andrasik et al., 1982; Arena et al., 1984), also using self-reportineasures of anxiety, have found either no relationship between anxiety and 


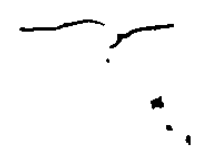

headache, or only a weak one. In the present study however, șome evidence was found which suggests that a subject's perceived locus of control and level of assertiveness may affect the amount of anxiety reported.

Previous studies have shown that subjects with a more external locus of control, tended to report more anxiety (e.g. Carter, 1983; Lefcourt, 1981; Ray \& Katahn, 1968, Watson, 1967). Assertiveness has also been linked to reduced anxiety (Brooks \& Richardsón, 1980; Waksman, 1984), and Waksman, 1984 also found that an internal locus of control was related to reduced anxiety. The present study confirms these findings and also shows a relationship between internal. locus of control and higher assertiveness. Pear\$on Product-Moment correlations between the three personality variables (LC, RAS, and ANX), indicate that subjects, who tend to be internal and more assertive also tend to report less anxiety.

- Possibly thén, anxiety would be more strongly related to headache if the effect of locius of control and assertiveness was taken into account. This proposition is party borne out by the finding that anxiety has a significant amount of unique variance with headache $\boldsymbol{r}$ frequency and yet does not contribute significantly when IC and RAS are included. (See Table 17). Using. the 16PF measure of anxiety then, does not seem particularly useful in predictingeheadache frequency or severity. In 


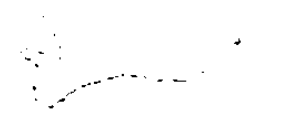

fact, any self-report measure of anxiety would be influenced by the subject's reluctance or willingness to admit to it. The subject may not be accurately reporting his or her level of anxiety, as it may be affected by the level of assertiveness and/or perceived locus of control. Although significant correlations exist between reported anxiety and the measures of headache, no significant differences were found on headache severifty or frequency, between the two groups representing lober. and higher anxiety. (Although, as shown in table 2?, the more anxious group does have higher mean scores for, both frequency and severity of headache). In other words, the level of reported anxiety does not have a strong effect on the frequency or severity of headaches.

The effect of locus of control alone is not strong enough to aifferentiate hetween headache activity. Neither. is the effect of assertiveness, although it may be a factor iri those reporting the most frequent headaches (see Table 18). However, as previously discussed, a relationship between reported anxiety and headache does exist and may be moderated by the subject's assertiveness and locus of control. It seems that when a subject is 'internal and more assertive, he-or she is more likely to report lower anxiety, than when external and - less asso Ke ive. Keeping in mind the positive correlation between anxiet $\bar{J}$ and headache, it is interesting to note 
from Table 14, that the two combinations with the greatest number of more frequent headachè sufferers, include both less anxious subjects (Combination Number 1), and more anxious subjects (Combination Number 2). This is also the case for headache severity (see Table 15). Further, in the group which reported weekly headaches $(n=59)$, the largest number of.subjecte (13) were internal, more assertive, and less anxious. This combination was followed closely by the 12 subjects classified as externai, less assertive, and more anxious..

A possible explanation for these findings is that mubjects who are internal and agsertive are denying the. full. extent of their anxiety, although their level of herduche activity is at least equal to those subjects who silat to more anxlety and are external and lese assertive. Although the present atudy found some evidence to support this explanation, further research lo needed. UBing galvanle skin reoponses (GSR) as. mosoure, the phyolologloil arousal of the tro groups, one belng Internal, wore asertive, and reporting 1008 . nnxingy, nnt the other) (extiornal, leas aseort ive and reporting core anxlety, oould be coapared. If the tro

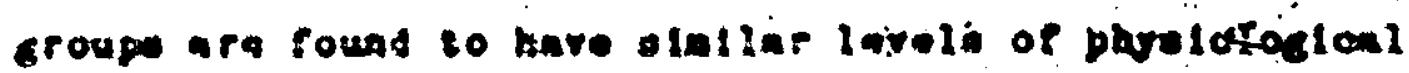

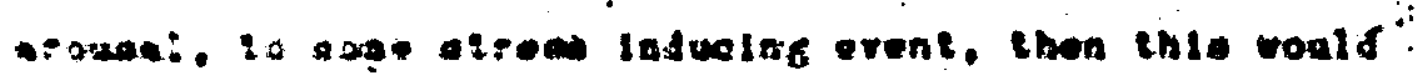

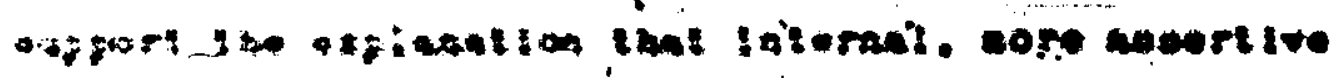

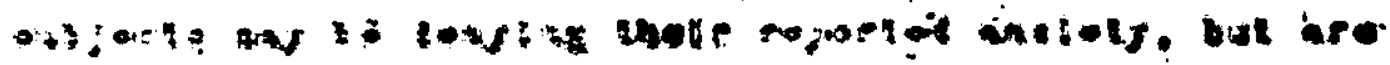


physiologically anxious.

- Utility of the HLC in Headache Research

The-study also suggests that the HLC is not a useful measure in headache research. "Its discrininant validity, in relation to Rotter's IC Scale, is demonstrated by the correlation between the two scales of $.26,(p<.01)$. This finding is sinilar to that of wallston et al. (ig76) who found a correlation of $.33,(\mathrm{p}<.01)$, between the HLC and the IC. It may be that a scale designed to specifically measure heälth expectancles is too limited to be of use with such a widespread complaint as headache. The IC taps locus of control beliefs across a wide variety of situations and was generally found to be more useful because of Its significant correlations with some of the other personality variables. Relationghipg Between the 16PF Factors and Headache The study àlso provides thoporturity to examine relationships between the headache measures and all the 16PF factors. Only two of the primary factora have olenlicint dorrelationa with the headache measures (0 and Q4), and both of thege account for a large part of the second order Pactor Arr. There correlations Indlente that those nubjecte vho roport aore erequent and gevere henductind tend so vory rore ur: be zore tenoe than thoue

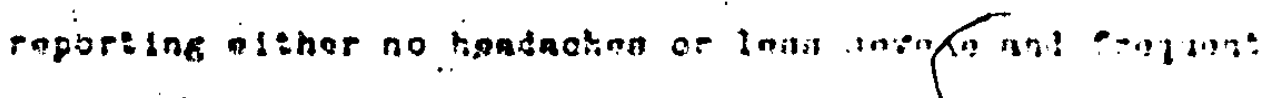

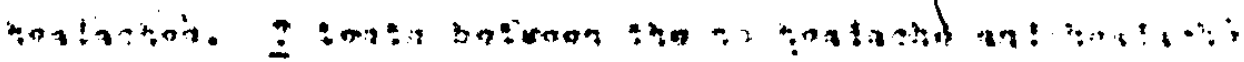


subjects also revealed a significant difference in Factor Q2, indicating that non-headache sufferers tend to be more self-sufficient and resourceful.

The "traditional" belief that higher intelligence is related to more frequent and severe headaches, particularly to migraine, receives no support from the present study. The Pearson Product-Moment correlations between Factor $B$ and headache frequency and severity are actually close to zero. Although Factor B is not a full scale intelligence test, it is commoniy accepted as being a reliable brief measure of intelligence, so this finding. appears valid. Further, the correlation betwe Factor $B$ and RAS, although nati signjficant $(\underline{r}=.13, \underline{p}=.06)$, suggests that subjects. whth higher intelligence tend to be more assertive. As assertiveness is shown to have a. aignificant negative correlation with headache severy, for subjects with weekly headaches (see Table 9), this would seem to further contraindiciate the premise that more Prequent headaches are assoclated with higher. Intelisence.

Relationship Between Sex of the Subject and Headache The best predictor of headache frequency found in thlis istuly lo the eex of the subject. Women are clearly shoin to report wore erequent headkehes than men, and SBX (1) foind to have a signifleant effoct vhen ueed as a cosurbte in a murcora with FRo as one of the dejendent 
variables. The finding that women report more headaches, is a common one in headache research (see Table I). As suggested by Ziegler et al. (1977) it may bp that ") " "menstrual migraine" accounts for soine of this difference. The present study offers some support for this explanation with "menstruation" 'listed as a precipitating factor by 54.5 percent of women (see Table 4). Of course it may be that, as group, men are also less willing to admit to headaches, possibly as an unconscious way to maintain an image of thergelves as the "stronger sex".

\section{Summary}

The weak relationship between anxiety and headaches found in the present study and often mentioned in the Iiterature, may be-due to the denial of roported anxiety by subjects who are internal and more asbertive and yet report substantial headache activity. These'subjects may nevertheless be at least as anxious, phyiglogically, as those who are external, less risaertive, ahd report more anxiety, agguming headache activity is a valid measure of physiological arousal to stress. Firther research could. provide additional evidence to support or reject this explanation, by measuring physiological arousal to a stress inducing stimulus, using, GSR techniques. The group which reports less anxiety and is internal and more assertive could be compared to the group which is 
external, less assertive and reports more anxiety. If the two groups are shown to have similar levels of physiological arousal, then the explanation offered for. the findings in the present gtudy would be supported. 2. Findingo Describing the Sample A. Headache Frequency and Severity

Generally, the present study has similar findings to several earlier studies, in terms of headache incidence: (See Táble 1). 'In particular, the findinga of Ziegler et al. (1977) correspond closely to those of the present study, for total incidence. (83.7\% found by Ziegler et: al., $82 \%$ in the present. study). However, other studies based on college student samples (Hicks \& Campell, 1983; Hicks \& Kilcourse, 1983; Ogunyemi, 1984), have indicated a lower incidence of headache, than the present study. These differences may be partly due to the type of question posed to the respondent. The present.. study agfas: $=$ the same question as Ziegler et al: (1977), which "Have you ever been subject to headache?" The ctwo studies by Hicks and $h \neq s$ colleagues askẹá: "Do you have tension or migraine headaches often?_ sometimes? never ?_." Ogunyemi asked: "Do younsuffer from recurrent headache occurring without associated illness -such as fever, rigora, yellow eyes, abdominal pain or cuugh?". questions posed by Hicks and also by Ogunyemi, would seem to have a tendency to illicit fewer affirmative 
responses. For instance, the respondent may have 'suffered from a type of headache which was not to be included in the study (e.g. headaches due to infections or allergies) or the respondent may have erred, on the conservative side; in his or her interpretation of"recurrent" or "sonetirnes". In the case of the Ogunyemi study, there may also be the possibility of cultural or racial differences in headache incidence. Certainly the type of question asked will have an effect on the headache incidence reported and has to be. taken into account when comparing studies. Nevertheless, it appears that the incidence of headache is increasing. (see Table I) and this may be more support for the involvenent of stress in headache. With increasing competition, both in the work place and between men and women in general, and the faster pace of modern life, the amount of stress in the environment has also increased. $\therefore$ It would seem that if we expect to avoif stress related disorders such as heddaches, the development of coping skills is critical, as is research into the etiology of these disorders.

The present study also indicated that a substantial nunber of the subjects (47.6\%) consider their headaches to be either severe or disabling. Also, about 32 percent. experience weekly headaches. As shown by the strong positive correlation between headache severity and 


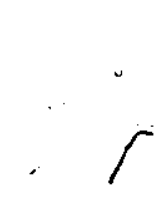

Prequency ( $\underline{r}=.76, \underline{p}<.01)$, those who rate their headaches as more severe tend to experience them more frequentiy. The present findings then, seen to be in - fairly close agreement with the general population studies shown in the literature (e.g. Turner, Stone $\&^{\circ}$ Stone, 1979; Ziegler et al., 1977), and re-emphasize not only the pervasive nature of headache, but also the subjective perception of it as a substantial source of pain and misery.

\section{B. Headache Type}

In relation to types of headache, the findings of the present study indicate that the type of headache (i.e. migraine, tension, or combined), has no effect on:

the reported severity or frequency of headache. This finding is at variance with many other studies (e.g. Andrasik et al.,.1982; Cohen \& McArthur, 1981; Thompson, 1982), which have found migraine headaches to be the most severe (or intense) and tension headachea to have the most erequent rate. However, as pointed out earlier, the method $\delta f$ classification used (based on Arena et al.,' 1982); has only 68 percent accuracy rate and thereforos cannot be considered very exact. Nevertheless, this: method of classification has value in that it would seem to be more reliable than the judgment of a lone. experimenter. Also it is certainlý less costly, in terms of time and money, than employing the services of one, or 
$\int_{\text {more, expert headache ditgnosticians. }}$

Further, the present study does not show any

significant differences between either the three headache types or the headache sufferers vs. the non-headache subjects, when measured on the three personality variables. It seems then that the type of headache experienced by the subject has no relationship to his or her level of assertiveness, amount of anxiety, or locus. of control. However, other researchers have not found this to be the case (e.g. Anderson \& Franks, 1981), with., a fairly consistent finding being that tension headache subjects are more anxious than migraineurs.

s" Overall, the present study suggests that classifying headaches into the categories proposed by the Ad Hoc Committee on Classiff́cation of Headache (1962), is not very useful. One group of researchers (Bakal, Kaganov, \& . Demjen, 1983) have' suggested that a more useful way to - classify headaches would be to view, "headache symptoms along a continuum of severity". (p.54). Bakal et al. allso - state that this view is "gaining recognition as a viable alternative to the tranditional method of headache classification" ${ }^{(9)}(p .45)$.

\section{Precipitating Factors.}

As shown in Table 4 , the psychological jopects ofe headache are well recognized by the subjects. It may be that this population (introductory psychology students) 
is more sophisticrted, in teras of psychological knowledge, and it would be interesting to compare these findings with those from a general population. The most frequently listed precipitating factors are, "Meñtal Stress; Mental and/or Physical Exhaustion, and Too Iittle Sleep. These factors seem to be interrelated. Too little sleep could certainly be a factor in exhaustion and mental stress can result in sleeping problems', which in turn can lead to exhaustion. The vast majority of the subjects list several factors as precipitating agents and it may be, as suggested by. Ogunyemi (1984), that this indicates a constitutional" predisposition to "muscuIar and vascular disturbancies by a host of external and internal factors". (p.130).

D. Other Psychosomatic Symptoms .

The finding that the number of other psychosomatic symptoms reported by subjects with headache, is greater than the number reported by non-headache subjects, is in - agrëement with. Andrasik ett al. (1982). Although the present study does not show significant differences between all the levels of severity on this measure, the trend is cọng̣istent. This suggests'that headache sufferers may be predisposed to pischosomatig disorders of various kinds, and thefefore.that headache may not be a unique symptom but one of several which together form a "psychosomatic syndrome": If this is the case then it 

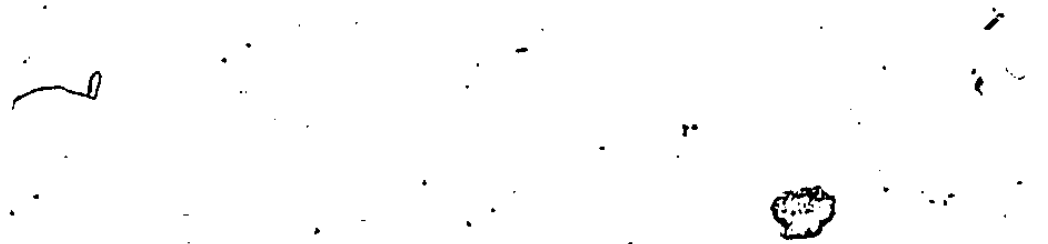

may not be possible to distinguish between subjects who suffer from different psychosomatic disorders, in terms of personality characteristics. .

As found with headache incidence, sex differences are also readily visible, with women reporting a greater number of other psychosomatic symptoms, on average. Either women are more willing to admit to symptoms than are men,. or women do..actualiy experience more symptoms.

- The present study does not attempt to resolve this issue, but it may be that locus of control is a factor in these sex differences. Women are generally more external than men and, as Iefcourt (1981) has suggested, those with a more external locus of control are more likely to report symptoms of stress. Presumably, this is because externals feel helpless with regard to influencing what happens to ther and are the refore more likely to acknowledge the presence of symptoms beyond their control. However, Lefcourt's suggestion is not borne out by the present study, as externals are not shown to report significantly more frequent or revere headaches, than. internals.

Summary

The present study has similar findings, for headache incidence, to earlie $\dot{r}$ studies of the general population. However, when compared to some other studies of headache incidence in university populations, the present findings 
show headache to be more prevalent. These differences mal be partly due to the type of question posed to the respondent. It appears that, over time, headacha $"$. incidence has been increasing and this may be due to increased sources of stress in the modern environment. The study emphasizes the pervasive nature of headache and - its perception as a substantial source of pain and misery .

Headache type does not have any effect on either headache frequency or severity, or on the scores obtained on the personality scales. These findings are at variance with many other studies and may be due to the : Pairly low accuracy claimed for the method of classification used.

The three most frequently listed precipitating factors seem.to be interrelated. Too littio sleep can be a factor in exhaustion and mental stress can lead to sleeping problems, which in turn can result in exhaustion :-

The number of other psychosomatic symptoms reported is greater for headache sufferers, than for non-headache sufferers. It appears that headache sufferers may be predisposed to warious kinds of psychosomatic disorders and this suggests that headache may not be a unique symptom, but one of oeveral, which together form a. "psychosomatic syndrome". 


\section{References :}

- Ad Hoc Committee on Classification of Headache. (1962). A classification of headache. Neurology, 12, 378-380.

Ajwani, J. \& Ajwani, M. (1983). Anxiety and depression in migraine and tension headache sufferers. Indian Journal of Clinical Psychology, 10, 107-112. Andrasik, F.J., Blanchard, E.B., Arena, J. G., Teders, S.J., Teevan, R.C., \& Rodichok, L.D. (I982). Psychological functioning in headache sufferers. Psychosomatic Medicine, 44, 171-182. Arena, J. G., Blanchard, E. B., Andrasik, F., \& Dudek,.B. C. (1982). The headache symptom questionnaire : Discriminant classificatory. ability and headache syndromes suggested by a factor analysis. Journal of Behavioral Assessment, 4 , 55-69.

Arena, J. G., Blanchard, F. B., \& Andrasik, F. (1984). The role of affect in the etiology. of chronic headache. Journal of Psychosomatic Research, 28 , 79-86.

Bakal, D. (1975). Headache : A biopsychological perspective. Psychological Bulletin, 82, 369-382. Bakal, D. (1979). Pgychology and medicine. New York : Springer.: : . 
Bạkal, D., Kagnov, J.,.\& Demjen, S. (1983). Headache assessment from a severity perspective. . In $k$. Holroyd, B. Schlote, \& H. Zenz (Eds.), Perspectives in research on headache (pp. 45-55). New York : Hogrefe. Brewis, M., Poskanzer, D. C., polland, C., \& Miller, H.'(1966): Neurological disease in an English city. Acta Neurologica Scandinavica : Supp. 24, 42.

Brooks, G., \& Richardson, F. (1980) Emotional skills training : A treatment program for duodenal ulcer. Behavior Therapy, il, 198-207.

Brown, G. (1973). Meaning, measurement and stress of Iife events." In B. S. Dohrenwerd, \& B. P. Dohrenwend (Eds.), Stressful life events: Their nature and effects (pp. 217-243). New York : John Wiley \& Sons, Inc.

Carter Jo. A. (1983). Locus of control., attitudes toward physionl activity and death anxiety. College Sturent Journal, 17, 236-239. Cattell, R. B., \& Eber, H. W. (I'g62). Supplement . of Norms for Fopris and B of the Sixteen Personality Factor Questionnaire. Champaign, Illinois : I.P.A.T. 
Cattell, R.., Eber, H., \& Tatsuoka;' $\dot{M}$. (1970). Handbook for the Sixteen Personality Factor Questionnaire (16PF). Champaign, IIlinois : I:P.A.T." Chattopadhyay, P. \& Mazumber, .P: (1982).

Physiological and self-report indices of arousal in tension-headache sufferers, Indian Psychologist, I, $56-60$.

Cohen, M., \& McArthur, D. (1981). Classification of . $\therefore$ migraine and tension headache from a survey of 10,000

- headache diaries: Headache, 21, 25-29.

Cuypers, J., Altenkirch, H., \& Bunge, S. (198I). Personality proflles in cluster headache and migraine. Headache, 느, 21-24. Friedman, A. (1979). . Muscle contraction headrche.

$\therefore \quad$ Anerican Family Practice, 20, 709-715.

Garvey, M., Schaffer, C.., \& Tuason, V. (1983). Relationship of headache to depression. British: Journal of Psychiatry, 143, 544-547.

Haan, N. (1982). The assessment of coping̈, defense, and stress. In L. Goldberger, \& S. Breznitz (Eds.), Handbook of stress .254-269. New York : MacMillan. Hicks, R., \& Campbell, J. (1983). Type A-B behavior and self-estimates of the frequency of headaches in college students. Psychological Reports; 52, 912. 
$\therefore \quad \div$

. $\lambda$, Hicks, R., \& Kilcourse, J. (1983). Habitual sleep.

$\therefore$ duration and the incidence of headaches in college students. Bulletin of the Psychonomic society, 21 , 119.

Hinsie, I.; \& Campbell, R. (1970). Psychiatric

Puctionary $(4 t h$ ed.). New York : Oxford Jniversity press. $x$.

Houston, B. $\dot{K} \cdot(1972)$. Control. over stress, locus of control, and résponse to stress. Journal of Personzlity and Social Poychology, $21,249-255$. Huber, H. P., Hubert, D. , \& Herper, R. (1982). Psychological and psychophysiological aspects In ? patients with Ionj-ter migraine histories. Studia Psychologica, 24; 263-273.

Krug, S. (I98I). Interpreting I6pf profile patterns. Çhampaign, II. : IPAT. Krug, Ș., Scheier, I., \& Catteīl, R. (1976) Handbook for the IPAT Anxiety Scale. Champaign, II. : IPAT".

Lazarus, R.S. (1966). Psychological stress and coping prócess. New York : McGraw will. Iefcourt, H. M. (1981).. The construction and, development of the multidimensionalmultiattributional causality scales. In H. Lefcourt (Ed)., Research with the Locus of Control construet (pp. 245-277). New 'York : Academic' Press. 
0

Martin, P. (1983). Behavioral research on headaches : Current status and future directions. In K. Holroyd, B. Schlote, \& H. Zenz (Eds.), Perspectives in research on headache (pp. 204-215). New York : Hogrefe.

Matarażo, J., \& Carmody, T. (1983). Health psychology. In $\dot{M}$. Hersen, A. Kazdin, \& A. Bellack (Eds.), whe clinical psychology handbook (pp. 657682). New York: Pergamon Press.

Mechanic, D. (1962). Students understress. New York : MacMillan.

Ogden, H. D. (1952). Heardache studies. Statistical data I. Procedure and sample distribution. Journal of AIlergy, 23, 58-75. Ogunyemi, A. $\overline{0}$. (1984): Prevalence of headache among Nigerian university students. Headache, 24, 127-130. Rathus, S.A. (1973). A 30 item schedule for. assessing assertive behavior. Behavior Therapy, 4, $398-406$.

Ray, W. J.'\& Katahn, M. (1968). Relation of anxiety to locus of control, Psychological Reports, 23, 1196. Reed, M: (1980). Endorphin update. Headache, '20, 146. Rotter, J. (1966). Generalized expectancies for internal va. external control of reinforcement. Psychological Monographs, 80, (1, whole No. 609). 
Sargent, J. D. (1982). Stress and headaches. In

I. Gojlaberger \& S. Breznitz (Eds.), Handbook of stress - (pp. 599-610). New York : MacMillan.

SAS Inftitute Inc. (1982). SAS user's guide:

Othtistics, 198? edition. Cary, NC:SAS Institute Inc.

Sezye, H: (2978). Revised edition. The stress of

life. New York : MaGraw Hill.

Steptoe, A. (1980). Stress and medical disorders. In

S. Rachran (Ed.), Contributions to medical.

psychology (Vol. 2, pp. 55-77). New York : .

Pergamon Press.

Tabachnick, B., Fidell, T. (1983). Using multivariate

itatisticg): New York : Harper \& Row.

Tfelt-Hansen, P., Jolis, I., k Olsen, J. (198.L). " .

Prevalence and significance of muscle contraction

tendencies during coinmon migraine attacks. Headache,

21 , 49-54.

Thompson, T.K. (1982). Diagnosis of head pain : An

idiographic approach to assessment and classification

Headache, 22, 221-232.

Turner, D., Stone, A., Re Stone, M. (1979). Headache

and its treatinent : A randon sample survey. Headache, :

19, 74-77.

Waksman, S. A. (1984). Assertion training with

adolescents. Adolescence, 14, 123-130. 
Watlston K, \& Wallston B. (198I). Health Locus of Contröl scales: In H. Lefcourt '(Ed.), Research with the Locus of Control construct (pp. 189-243). New

York : Academic Press.

Wallston, B., Wallston, K., Kaplan, f., \& Maides, s. (1976)." Development and validation of the Health Liocus of Control (HLC) Scale, Journal of

rongulting and Cl in ical Psychology, 44, 580-585. Waters, W. E., (1974). The Pontypridd headache survey. Headache, 14., 81-90,

Vaters, W. E., \& O'Connor, P. J., (1970)'. The clinical validation of the headache questionnaire. In Background to Migraine, Vol. 3. Iondon : : Heinemani:

Waters, W. E., \& O'Connor, P. J. (1975). Prevalence of migraine: Journal of Neurology, Neurosurgery, and Psychiatry, 38, 613-616. Watson, D..(1967). Relationship between locus ,of control and anxiety. Journal of Personality and Social Psychology, $6,91-92$.

'Weiss, E., \& Ėnglish, 0. (1957). Psychosomatic . medicine (3rḍ ed.). Philadelphia : W. B. Saunders. . : Wolff, H. G. (1963). Headache and other head pains. Y New York : Oxford University.Press. 


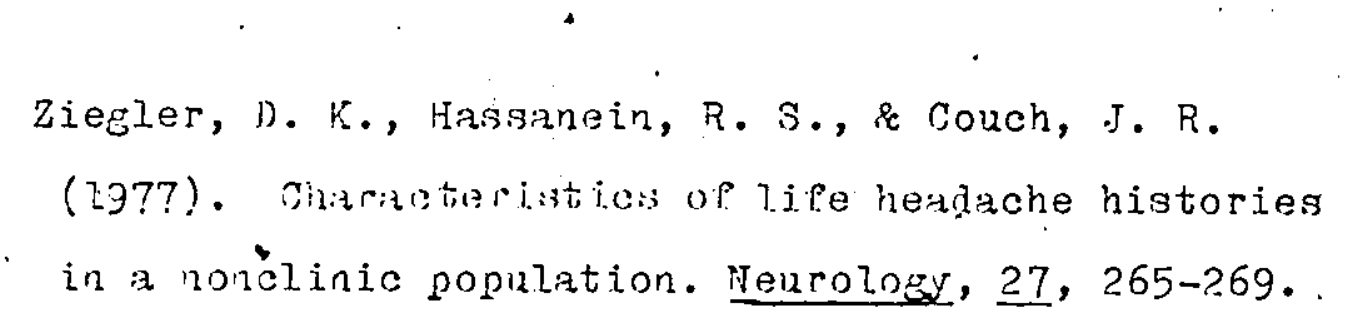

in a nonclinic population. Neurology, 27, 265-2.69. 
Appendix A. .

Descriptions of Headache Types.

(Based on the Ad Hoc Committee on Classification of Headache, 1962).

1. Vascular headaches of the migraine type.

Recurrent attacks with a wide variation in frequency, intensity and duration. Usually unilateral in onset and sometimes associated with nausea, vomiting and prodromal symptoms (e.g. visual, sensory or-motor disturbances). Cranial arteries become distended and dilated and the pain in usually experienced as "thirobbing" or "pulsating". This category includes cluster headaches (those attacks occurring in closely packed groups separated by long remissions) and lower face headaches.

2. Tension or muscle-contraction headaches.

Widely varied in intensity, frequency and duration, associated with contraction of the scalp or neck muscles. Usually bilateral, the pain is often experienced as "aching", "tight", or "band-like".

3. Combined headache.

Combinations of migraine type with tension type, co-existing. in the attack.

4. Headaches associated with nasal discomfort. Not due to allergies or gross anatomic defects.

5. Psychogenic headaches.

No physical basis for the pain and the prevailing clinical disorder is a delusional or conversion reaction.

6. Other.

Includes headaches due to systemic infections, hypértension, poisoning, organic disorders, (such as tumors), and diseases of ocular, aural, sinus and nasal, dental, or other cranial structures. . 
Appendix $\underbrace{\text { B. }}$

HEALTH LOCUS OF CONTROL SCALE

INSTRUCTIONS

92

INDICATE YOUR AGREEMENT OR DISAGREEMENT TO EACH OF THE FOLLOWING STATEMENTS BY USING THE CODE BELOW.

1. STRONGLY DISAGREE

2. QUITE STRONGLY DISAGREE

3. DISAGREE.

4. AGREE

5. QUITE STRONGLY AGREE

6. STRONGLY AGREE

1. If I take care of myself, I can avoid illness.

2. Whenever I get sick it is because of something I've done or not dore.

3. Good health is largely a matter of good fortune.

4. No matter what I do, if I am going to get sick I will get sick.

5. Most people do not realize the extent to which their illnesses are controlled by accidental happenings.

6. I can only do what fify doctor tells me to do.

7. There are so many strange diseases around that you can never know how or when you might pick one up.

8. When I feel ill, I know it is because I have not been getting the proper exercise or eating right."

9. People who never get sick are just plain lucky.

10. People's ill health results from their own carelessness:

11. I am directly responsible for my health. 
Appendix,$C$

CIRCLE EITHER STATEMENT

MORE STRONGLY BELIEVD TO
ROTTER LOCUS OF CONTROL SCALE

IISTE.UCTIONS-

THE CASE AS FAR AS YOU'RE،CONCERNED.

1. a. Chlldren gat Into trouble because thoir parents punish them too much.

b. The troublo with most children nowadeys is that their paronts ore tco easy with thon.

2. a. Many of the unhappy things in peonlo's lives are partly due to bad luck.

b. People's misfortunas result from the mistakes they mako.

3. a. One of the major reasons why we have wars is because people don't take enough interest in politics.

b. There will aiways be wars, no matier how hard people try to provent them.

4. a. In the long run people get the respect they deserva in this ropld.

b. Unfortunately, an individual's viorth'often passes unrecognlzed no matter how hard he tries.

5. a. The idea that teachers aro unfair to students is nonsense.

b. Host students dont realizethe extent to which their grades are influenced by ascidental happonings.

5. D. Without the right breakseone cannot bn an effective leador.

b. Capable peeple who fail to become leaders have not taken advantage of their opportunities.

7 7. d. No matter how hard you try some people just don't like you. b. Poople wio can't gist others to like thim don!t understand how to got
along with othors.

6. a. Herodity plays the major role hr.detemining one's personallty

b. It is one's experiences in lifo which determinos what you'ze liko.

2. a. I have ofter found that what is golrig to happon will happon.

b. Trusting to fate has never. turned out as vell for me as making a dacision to take a definite course of action.

10. a. In the case of the vell pronered student there is rarely if ovor such a thing as an unfair test.

b. Many timos exam questions tend to be so unrolated to courso work that studying is really useless.

11. 8. Becoming a success is a matter of hard work, luck has littile or nothing b. Getting a good job dopends mainly on being in the right place at the
rlght time.

12. a. The overage citizen can have an influence in government decisions.

b. This world is run by tho fou pecplo in powar, and there is not much the little guy can do about it.

13. a. : then 1 make plaris, 1 am_dilmost certain that 1 can make them work.

b. It is not always wige tolplan too for ahead because many things"turn out to be a matter of good or bad fortune anyhow. 
14. a. There are certain peorle who are just no good.

b. Thare is some goos in everybody..

15. a. In my case gotting withat I kant has little or nothing to do with luck.

b. Many timos wo might just as well decide what to do by flipping a coin. 16. a. Who gots to be the boss often deperids on who was lucky enough to bifti:
the right place first.

b. Getting pooplo to do the right thirg depends upon ability, luck has littlo or nothing to do with it.

17. a. As far as world affairs aro concerred, most of us are the victims of forces we dan neithar understand, oor control.

b. By taking an activo part in political and social affairs the people can control korld events.

18. a. Most peoplu don't realize tho exicnt to. which their lives are controlled by accidental happenings.

b. There really is no such thing as "iuck.".

19. a. One should alhays be willing to adrit mistakes.

b. It is usually best to cover up one's mistakes.

20. a. It is hard to kno: whether or nat a parson really likes you.

b. How many friends you have deperids upon hov nice a parson you are.

21. a. In the long run the bad things thet hepoen to us are balonced by the good ones.

b. Host misfortunes are the result of lack of ability, ignoranco, laziness, or all three.

22. a. With enough effort we can wipe net solitical corruption.

b. It if difficult for people to have much control over the things pol ificians do in office.

23. a. Sometimos, I can't understand how teachers arrive at the...grades they glve. b. There is a diract cornection biatwe sn how hard I study and the grades 1 get.

'24. a." A good leader expects poople to decids ior thamselves what they should do. b. A good leader makes it clear to everybedy. What thieir jobs are.

25. a. Many times I feal thiat I have little influence over the things that. happen to me.

b'. It is inpossible for me to believe that chance or luck plays an Important role in my life.

26. o. Peoplo ore lonely beciause they dan't try to he friendly.

b. There's not much us? in trying tos hard to please people, if they like you, they like you.

27. o. There is too much èmphasis on athletics in hight school."

b. Team.sports are an excellent way to build character.

23. a. What happens to me is my own doing
b. Sometimes I feel that I don't have enough control over the direction my life is taking.

29: a. Most $f$ the time 1 can't understand why politicians behave the way they do.

b. In the long run the people are responsible for bád government on a national as vell as on a local lesvel. 
Appendix D

RATHUS ASSERTIVENESS SCBEDULE

INSTRUCIIONS

INDICATE HOW CHARACTERISTIC OR DESCRIPTIVE EACH OF THE FOLLOWING STATEMENTS IS OF YOU BY USING TḤE CODE BELOW

$\begin{array}{ll}+3 & \text { VERY MUCH LIKE ME } \\ +2 & \text { RATHER IIKE ME } \\ +1 & \text { SIIGHTIY IIKE ME } \\ -1 & \text { SLIGHLY UNLIKE ME } \\ \text {-2 } & \text { RATHER UNLIKE. ME } \\ \text {-3 } & \text { VERY UNLIKE ME. }\end{array}$

1. I have hesitated to make or accept dates because of "shyness".

2. When the food served at a restaurant is not done to my satisfaction, I complain about it to the waiter or. waitress.

3. I am careful to avoid hurting other people's feelings, even when I feel that I have been injured.

4. When I am asked to do something, I insist upon knowing why.

5. To be honest, people often take advantage of me.

6: I often don't know what to say to attractive persons of the opposite sex.

7. I will hesitate to make phone calls to business establishments and institutions.

8. I would rather apply for a job or for admission to a college by writing letters than by going through with personal interviews.

9. I find it embarrassing to return merchandise.

10. I have avoided asking questions for fear of siounding stupid.

11. During an argument I am sometimes afraid that $I$ will get so upset that I will shake all over.

12. I avoid arguing over prices with clerks and salesmen.

13. If someone has been spreading false and bad stories about me, I., see him (her) as soon as possible to "have a talk" about it.

14. I often have a hard time saying "No".

15. I tend to bottle up my emotions rather than make a scene.-

16. I complain about poor service in a restaurant and elsewhere.

17. Anyone attempting to push ahead of me in a line is in for a good battle.

18. I am quick to express an opinion.

19. There are times when I just can't say anything. 
Appendix E.

Descriptions of the 16PF Factors

(Based on Catell, Eber, and

Tatsuoka, 1970)

LOW SCORE DESCRIPIION

RESERVED, Detached, Critical, Aloof

IESS INTELIIGENT, Concrete Thinking

AFFECTED BY FEEIINGS, Emotionally Less Stable, Easily Upset

HUMBLE, Mild, Accommodating, E Conforming

SOBER, Prudent, Serious,

Taciturn

EXPEDIENT, Disregards Rules,

Feels Few Obligations

SHY, Restrained, Timid,

Threat-Sensitive

TOUGH-MINDED, Self-Reliant, I

Realistic, No-Nonsense

TRUSTING, Adaptable, Free of I

Jealousy, Easy to Get Along

with

PRACTICAI, Caréful,

Conventional, Regulated by

External Realities, Proper

FORTHRIGET, Natural, Artless, N

Unpretentious

SELF-ASSURED, Confident, Serenè 0

CONSERVATIVE, Respecting

Established Ideas, Tolerant

of Traditional bifficulties

GROUP-DEPENDENT, A "Joiner"

and. Sound Follower

UNDISCIPLINED SELF-CONFIICT,

Follows Own Urges, Careless

of Protocol

RELAXED, Tranquil, Unfrustrated $Q 4$
- $\mathbf{A}$

B.

C

F

G

H

I

I

M

Q1

Q2

Q3

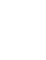

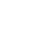

.

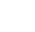

G.

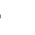

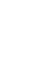

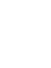


Appendix E continued

LOW SCORE DESCRIPTION

INTROVERTED

LESS ANXIOUS,

Adjusted.

SENSITIVE, Emotional,

Subjective

DEPENDENT, Subdued

$\therefore \quad: f$

6

I.

SECOND ORDER FACTORS

EXTRAVERSION

EXTRAVERTED

ANXIETY 1 MORE ANXIOUS

TOUGH POISE

HIGH SCORE DESCRIPTION

97

TOUCH POISE

TOUGH POISE, Alert, Cheerful, objective

INDEPENDENCE

INDEPENDENT 
Appendix $\mathbf{F}$.

HEADACHE QUESTIONNAIRE

98

PLEASE COMPLETE ALL RELEVANT QUESTIONS

Thank you for your participation. This survey is being made in order to determine the incidence and types of stress indicators existing in students at the University of Windsor. In particular it is mainly intended to examine the correlation between how stress is handled and headache symptoms. All information is confidential and will be used for statistical data only.

Colin Jones, Graduate Student, Department of Psychology, University. of windsor.

1. Mark " $X$ in in the appropriate box.

INSTRUCTIONS

2. Where additional information is requested please be brief and accurate.

3. Some questions have more than one answer. In such cases mark an " $X$." by EACH answer which applies.

4. Please fill out the questionnaire as completely as you can.

SECTION A

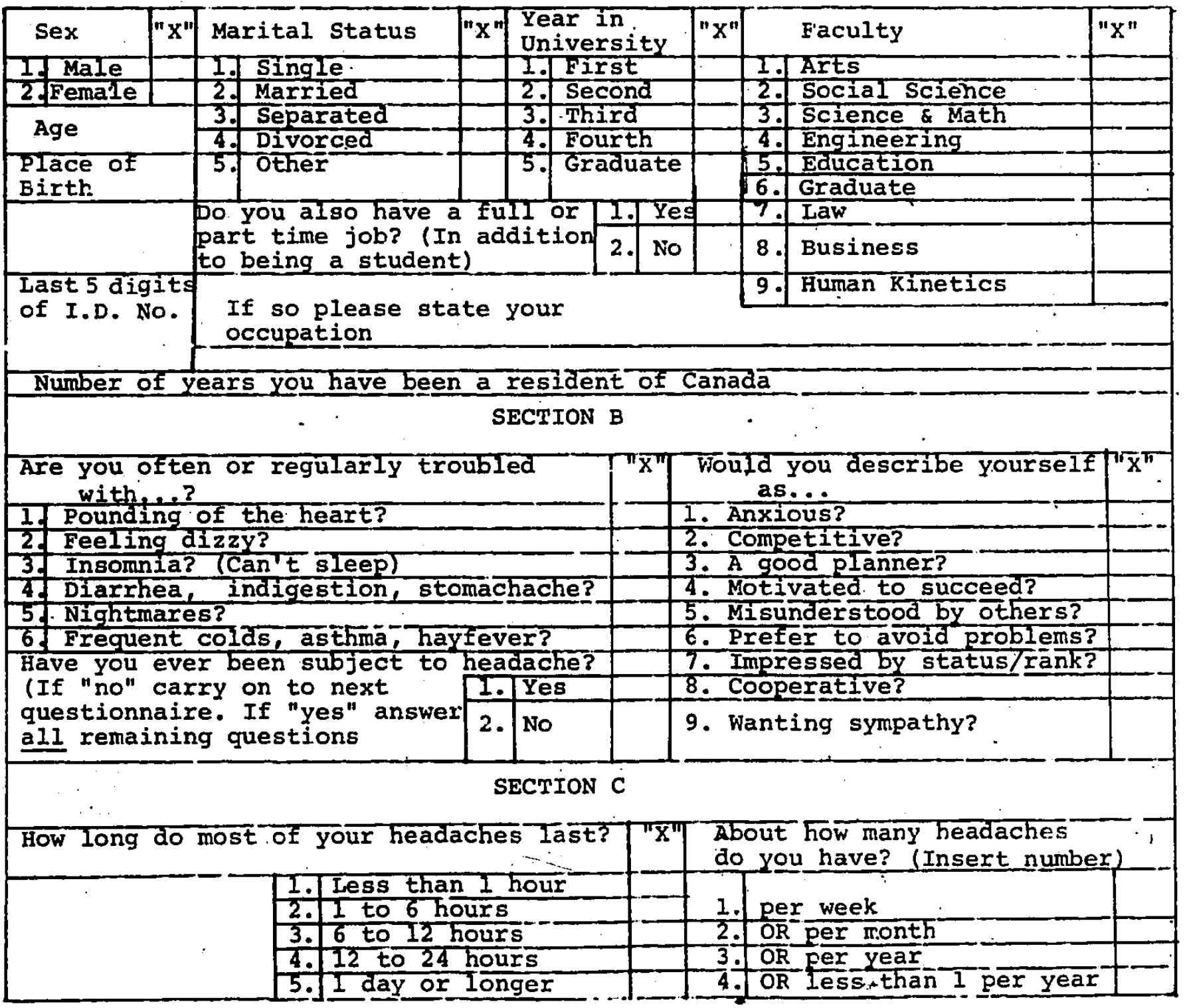




\section{SECTION C (CONTINUED)}

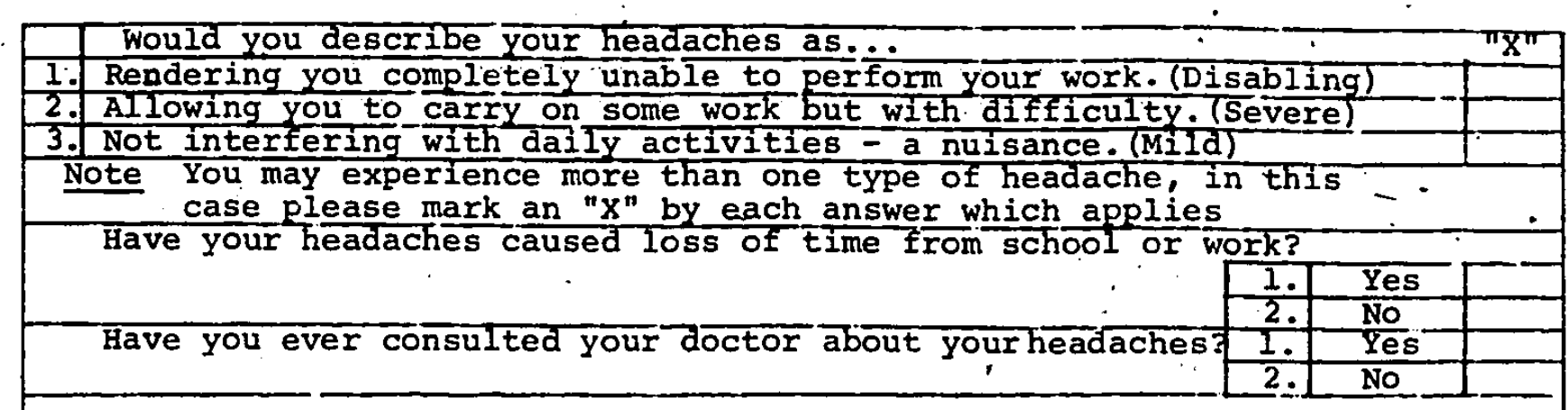

Please answer the following 16 questions by placing an " $\mathrm{X}$ " in the appropriate boxes.

\begin{tabular}{|c|c|c|c|c|c|c|}
\hline \multicolumn{2}{|r|}{ (1) } & NEVER & $\begin{array}{l}\text { IN- } \\
\text { FREQUENTLY }\end{array}$ & $\begin{array}{l}\text { SOME- } \\
\text { TIMES }\end{array}$ & USUALXY & ALWAYS \\
\hline 1. & I awaken with headaches. & & & & & \\
\hline 2. & My headache ends within 24 hours & & & & & \\
\hline 3. & I have sudden attacks of headaches & $\dot{-}$ & & & & \\
\hline 4.1 & $\begin{array}{l}\text { My headache is worse at the end of } \\
\text { the working day }\end{array}$ & & & & & \\
\hline 5. & $\begin{array}{l}\text { My headache is throbbing or } \\
\text { pulsating }\end{array}$ & & & & & \\
\hline 6. & $\begin{array}{l}\text { My headache can be described as a } \\
\text { feeling of tightness or external } \\
\text { pressure on my head (band-like or } \\
\text { cap-like) }\end{array}$ & & • & - & & \\
\hline 7. & $\begin{array}{l}\text { My headache begins on one side of } \\
\text { my head }\end{array}$ & & & & & \\
\hline 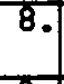 & $\begin{array}{l}\text { My headache starts in the neck, } \\
\text { shoulder or back of the head }\end{array}$ & & & & & \\
\hline 9.1 & $\begin{array}{l}\text { My headache is associated with } \\
\text { visual changes like seeing stars, } \\
\text { blind spots, double vision and/ } \\
\text { or intolerance, to light }\end{array}$ & & & & & \\
\hline 10. & $\begin{array}{l}\text { I have nausea and/or vomiting } \\
\text { wi.th my headache }\end{array}$ & & & & & \\
\hline П1. & $\begin{array}{l}\text { My headache gets worse if I } \\
\text { strain, cough or lift things }\end{array}$ & & $=$ & & & \\
\hline 12. & $\begin{array}{l}\text { My headache is better if I can } \\
\text { loosen up my neck muscles. }\end{array}$ & & 1 & & & \\
\hline 13. & $\begin{array}{l}\text { Aspirin, Anacin, Bufferin, } \\
\text { Excedrin, Tylenol and similar } \\
\text { drugs relieve my headache }\end{array}$ & & • & & & \\
\hline 14. & $\begin{array}{l}\text { I take a prescribed medication to } \\
\text { prevent a full-blown headache } \\
\text { attack }\end{array}$ & & $\checkmark$ & & & \\
\hline 15. & $\begin{array}{l}\text { My headache starts during periods } \\
\text { af relaxation }\end{array}$ & - & & & & \\
\hline 16. & $\begin{array}{l}\text { My headache starts during periods } \\
\text { of stress. }\end{array}$ & & & & & \\
\hline
\end{tabular}


Which of the following do you think bring on your headaches?

(" $X$ " any number that are relevant)

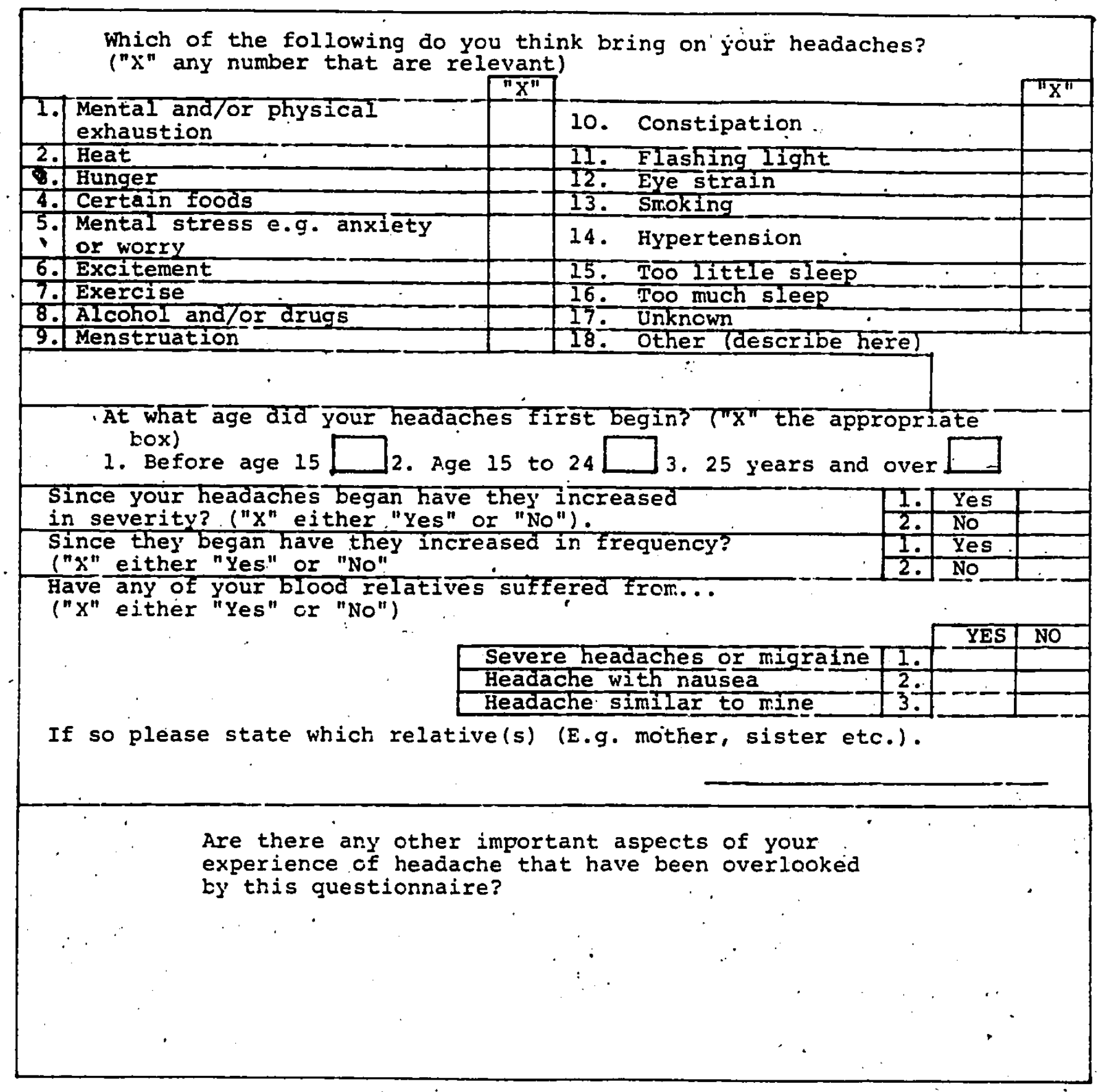

Are there any other important aspects of your experience of headache that have been overlooked by this questionnaire? 
Appendix G.

Median Splits for Each of the Variables

Variable. If $<$ this value then Level 1 , if $\geqslant$ then Level 2

$L C^{b} \quad 12$

RAS 48

ANX $\quad 65$

FREQ ${ }^{a}$ If FREQ $=1,2$, or 3 then Level $=1$, else Level $=2$

Notes

$\mathrm{SEV}^{\mathrm{a}}$ If $\mathrm{SEV}=1$ then level 1 , else Level $=2$

a These variables were also dichotomized at different levels, " depending on the analysis they were involved in. Cases where a different dichotomy was employed are shown in each table.

b If level $i$ then IC is referred to as "internal", if level 2 referred to as "external". 
1971 Finigrated to Canada from Wales with my wife and two daughters.

1983. Bachelor of Arts Degree (Honors Psychology) from The University of Western Ontario. (Completed pirti-tine whilst in pirzl-tine employment): 